bioRxiv preprint doi: https://doi.org/10.1101/2021.11.16.468807; this version posted November 18, 2021. The copyright holder for this preprint (which was not certified by peer review) is the author/funder. All rights reserved. No reuse allowed without permission.

\title{
HSP70-driven molecular response to the proteasome machinery inhibition is a vulnerability in cancer
}

Magdalena Oroń 1, Marcin Grochowski 1, Akanksha Jaiswar 1, Magdalena Nowak-Niezgoda ${ }^{2}$, Małgorzata Kołos ${ }^{2}$, Wojciech Kaźmierczak ${ }^{3}$, Tomasz Olesiński ${ }^{3}$, Małgorzata Lenarcik ${ }^{3}$, Magdalena Cybulska ${ }^{3}$, Michał Mikuła ${ }^{3}$, Alicja Żylicz ${ }^{4}$, Katherina Zettl ${ }^{5}$, Jacek R. Wiśniewski ${ }^{5}$, Dawid Walerych ${ }^{1}, *$

${ }^{1}$ Mossakowski Medical Research Center PAS, Warsaw, Poland

${ }^{2}$ Central Clinical Hospital of Ministry of Interior and Administration, Warsaw, Poland

${ }^{3}$ National Center of Oncology, Warsaw, Poland

${ }^{4}$ International Institute of Molecular and Cell Biology, Warsaw, Poland

${ }^{5}$ Max Planck Institute of Biochemistry, Martinsried, Germany

* Correspondence: $\underline{\text { dwalerych@imdik.pan.pl }}$

\section{Abstract}

Human neoplasias are often addicted to the cellular proteasome machinery. This has led to the development of bortezomib and carfilzomib proteasome inhibitors, approved for the treatment of multiple myeloma. Cancers, however, were found resistant to the proteasome inhibition in clinical trials, suggesting effective, cancer-specific compensatory responses. Here we employed global proteomics to determine contributions of compensatory mechanisms upon the proteasome inhibition with carfilzomib - in the cells of multiple myeloma, normal fibroblasts and cancers of lung, colon and pancreas. A pathway-oriented siRNA screen based on proteomics results showed that molecular chaperones, autophagy- and endocytosis-related proteins are cancer-specific vulnerabilities in combination with carfilzomib. HSP70 family chaperones HSPA1A/B were the most universal proteasome inhibition responders in the proteomes of all the studied cell types and HSPA1A/B inhibition most specifically sensitized cancer cells to carfilzomib in cell lines, patient-derived organoids and mouse xenografts. Overlap of proteomics with RNA-seq data showed that the proteasome inhibition-dependent HSPA1A/B induction in cancer cells is mainly transcription-driven and HSF1/2-depedent. Consequently we found that high level of $H S P A 1 A / B$ mRNA is associated with a low proteasome activity in cancer patient tissues and is a risk factor in cancer patients with the low level of expression of the proteasome. Functionally, the HSPA1A/B induction does not affect a proteasome expression bounce-back upon the carfilzomib treatment, while it supports other mechanisms of the proteasome inhibition response - autophagy, unfolded protein response and directly the $26 \mathrm{~S}$ proteasome activity. We found that the $26 \mathrm{~S}$ proteasome is chaperoned and protected from the inhibition with carfilzomib by HSPA1A/B assisted by DNAJB1 co-chaperone in cancer cells and using purified protein system in vitro. Thus, we define HSPA1A/B as a central player in the cellular compensatory response to the decreased proteasome activity, and the sensitive target in cancer cells with the inhibited proteasome. 


\section{Introduction}

Proteasome machinery is the central player in the controlled cellular protein degradation in eukaryotic cells (Collins and Goldberg, 2017). It consists of the $20 \mathrm{~S}$ catalytic core capable of degrading a significant proportion of cellular proteins independently of ubiquitination (Kumar Deshmukh et al., 2019), supplemented by 19 S regulatory caps providing a substrate polyubiquitination dependence (Rousseau and Bertolotti, 2018). Specific core subunits are replaced by alternative proteins in immunoproteasomes - responsible for peptide processing in antigen presentation (Murata et al., 2018). The catalytic core of all these proteasome forms possess three main proteolytic activities, in the $26 \mathrm{~S}$ proteasome termed: chymotrypsin-like, trypsin-like and caspase-like. The first of them is rate-limiting (Kisselev et al., 1999), and thus its targeting with inhibitors affects major proteasome functions in cells (Teicher and Tomaszewski, 2015).

Neoplastic cells were found be addicted to the activity of the proteasome machinery, which enables degradation of tumor suppressors and allows to sustain protein homeostasis in transformed cells (Chen et al., 2017; Tsvetkov et al., 2018). Therapeutic proteasome inhibitors, pioneered by bortezomib, have been successfully utilized in multiple myeloma treatment (Teicher and Tomaszewski, 2015). However, they were found relatively ineffective in solid tumors in clinical trials (Huang et al., 2014), while multiple myeloma patients have frequently developed resistance to the bortezomib treatment (Murray et al., 2014). Thus, second generation inhibitors were developed, including carfilzomib, which is approved for a relapsed/refractory multiple myeloma treatment (Groen et al., 2019). The drug is more specific than bortezomib, effective towards 20S, 26S and immunoproteasome by irreversibly inhibiting the chymotrypsin-like proteasome activity, and at higher concentrations - the caspase- and trypsin-like activities (Arastu-Kapur et al., 2011; Berenson et al., 2014; Kuhn et al., 2007). Nevertheless, introduction of carfilzomib has not resolved the problem of cancer's resistance to the proteasome inhibition, suggesting an existence of effective cancer-specific compensatory responses (Manasanch and Orlowski, 2017).

Several mechanisms have been put forward as the compensatory responses to the proteasome inhibition in neoplasias. Expression of 26S proteasome subunits is increased during a bounce-back response to proteasome inhibitors, mediated mainly by NRF1 (NFE2L1) (Radhakrishnan et al., 2010) and NRF2 (NFE2L2) optionally in conjunction with mutant p53 (Walerych et al., 2016). Components of the autophagy-lysosome protein degradation system are upregulated on proteasome inhibition (Ding et al., 2007; Min et al., 2014). Concomitant inhibition of proteasome and autophagy pathways was beneficial in treating models of several cancer types, including breast, pancreatic and hepatocellular carcinoma (Hui et al., 2012; Li et al., 2016; Yao et al., 2012). Proteins accumulating on the proteasome inhibition induce an unfolded protein response (UPR), which can lead to a context dependent cell death or survival which can be both affected by drugs targeting UPR in neoplasia (Borjan et al., 2019; Obeng et al., 2006; Vandewynckel et al., 2016; Vangala et al., 2020). Accumulation of misfolded proteins leads also to an induction of molecular chaperone proteins, including members of HSP70, HSP90 families of chaperones and DNAJ and BAG families of cochaperones (Awasthi and Wagner, 2005; Bush et al., 1997; Liao et al., 2006; Minoia et al., 2014). Targeting these proteins was considered to increase effects of proteasome inhibitors in neoplasia (Belalcazar et al., 2017; Huang et al., 2020b; Yerlikaya et al., 2010), however the extent and mechanisms of chaperone response to the proteasome inhibitors has not been well elucidated.

In this study we employed a global proteomics approach to compare in an unbiased manner the contributions of different compensatory mechanisms upon the proteasome inhibition with carfilzomib in cells of multiple myeloma, normal fibroblasts and cancers of lung, colon and pancreas. The cancer types were chosen based on highest predicted numbers of deaths they are predicted to 
cause in the upcoming decade among neoplasias of men and women altogether, in the US and the EU countries (Quante et al., 2016; Rahib et al., 2021). We identified the main HSP70 family stress inducible molecular chaperones HSPA1A and HSPA1B (often addressed jointly as HSPA1A/B thanks to nearly identical protein sequences(Smith et al., 2007)) as the most consequent proteasome inhibition responders in proteomes of all the studied cell types, and the cancer-specific vulnerability in combination with carfilzomib. We found that proteasome inhibition-dependent HSPA1A/B induction in cancer cells supports critical aspects of the proteasome inhibition response - autophagy, UPR and directly - the $26 \mathrm{~S}$ proteasome activity. Hence, HSPA1A/B is a main hub of the cellular compensation of the decreased proteasome activity in cancer cells.

\section{Results}

\section{Proteomics reveals similarities and differences in proteasome inhibition response in cancer, multiple myeloma and normal fibroblast cells}

In attempt to find a therapeutic window to specifically kill cancer cells using proteasome inhibition, we first compared their response to carfilzomib with multiple myeloma and normal cells. We tested viability in pairs of cell lines from three cancer types - lung, colon and pancreatic - against pairs of multiple myeloma cell lines and primary human fibroblasts, $24 \mathrm{~h}$ post treatment with increasing concentrations of carfilzomib (Fig. 1A). Multiple myeloma cell lines were the most sensitive to the proteasome inhibition, with a calculated IC50 at 8-12 nM of carfilzomib, while in the cancer cell lines IC50 was in a range of 66-326 nM and for normal fibroblasts - 424-512 $\mathrm{nM}$ of carfilzomib (Fig.1A, Table S1). Hence, cancer cells remained more sensitive to carfilzomib than normal cells, while multiple myeloma cells were several fold more sensitive than either of them. To investigate if this phenomenon was mirrored by changes in the proteasome activity, we determined carfilzomib's IC50s of the proteasome chymotrypsin-like activity in the same set of cell lines. In this experiment the normal fibroblast cells were the most sensitive to carfilzomib, while the cancer cells were on average the least sensitive (Fig. 1B, Table S1). As a result cancer cells and normal fibroblasts on average retained nearly $100 \%$ viability at $50 \%$ of the proteasome activity upon carfilzomib treatment for $24 \mathrm{~h}$ which was significantly higher than the multiple myeloma cells' viability (Fig. 1C). However, cancer cells had a significantly lower chymotrypsin-like proteasome activity at the $50 \%$ of their viability than the multiple myeloma cells, while it was significantly higher than the normal fibroblasts (Fig. 1D). This suggested that cancer cells possess response mechanisms which allow them to survive low proteasome activity similarly to normal cells and unlike multiple myeloma, while they additionally retain more proteasome activity than the normal cells under the carfilzomib treatment.

To understand molecular mechanisms underlying the specific features of cancer, multiple myeloma and normal cell responses to the proteasome inhibition, we performed a global proteomics analysis in lysates of the ten cell lines used in the experiments described above (Fig. 1E). The cells were treated with concentrations of carfilzomib which inhibited the chymotrypsin-like proteasome activity to $50 \%(+/-10 \%)$ at $24 \mathrm{~h}$ post treatment (Fig. $1 \mathrm{E}$; carfilzomib were concentrations based on the calculated IC50s of the proteasome activity from the Table S1, adjusted to the experimentally measured proteasome activity values). A label-free mass spectrometry analysis and a global protein approach with the sensitivity of over ten thousand identified proteins in a sample (Wisniewski, 2017a; Wisniewski et al., 2019) allowed for identification and quantification, across all four samples analyzed for each cell line, of more than seven thousand proteins in multiple myeloma and cancer cells and more than five thousand proteins in normal fibroblasts, (Fig. 1E, Fig. S1A, Table S2). 4137 proteins which were identified and quantified in each of the 40 samples analyzed overall, were used for hierarchical clustering analysis with Euclidean distance. This analysis revealed that the proteomes of the normal fibroblasts, cancer and multiple myeloma cells cluster separately (Fig. 1F). A differential 
analysis of protein level changes in carfilzomib-treated samples versus the DMSO-treated controls in each cell line (Table S2) showed only one hit significantly changing level $(\mathrm{p}<0.05)$ across all the cell lines - the main stress-inducible HSP70 family proteins, unified in the proteomics result due to a very high sequence similarity - HSPA1A/B (Fig. 1G, Fig. S1B). There were no specific proteins differing significantly in the six or five cancer cell lines versus the two normal fibroblast and the two multiple myeloma cell lines (Fig. 1G, Table S3). Most proteins significantly changing levels across multiple analyzed cell lines were either upregulated molecular chaperones or upregulated proteasome subunits (Fig. 1G). This suggested that the overall response to the proteasome inhibition is affecting similar proteins in different cell types, while the result of the hierarchical clustering of the studied proteomes indicated that broader, systems-biology analysis of the proteomics data is required to hunt for cancerspecific proteasome compensators.

\section{Molecular chaperone, autophagy and endocytosis-related proteins are vulnerabilities in the carfilzomib-treated cancer cells}

To confront systemic responses to proteasome inhibition in neoplastic and normal cell line groups we performed a comparative pathway analysis between changes in their proteomes. The proteins significantly changing levels $(\mathrm{p}<0.05)$ upon carfilzomib treatment in cancer, multiple myeloma and normal fibroblast cell lines were each fused into signatures, filtered for duplicates, and each signature was analyzed separately for enriched molecular pathways with association $\mathrm{FDR}<0.05$, followed by the result overlap aimed to find common and specific pathways (Fig. 2A, Table S4). The ClueGO tool analysis revealed cancer-specific pathways which represented cellular functions such as translation, mitochondrial metabolism, autophagy, UPR, MAPK signaling or endocytosis, as well as pathways common to cancer, multiple myeloma and/or normal cells (Fig. 2A). Similar pathways and functional protein groups were found by the Ingenuity Pathways Analysis (Fig. S2A). The pathways common to all three cell lines types were strongly enriched in the proteasome subunit proteins (Table S4) reflecting the bounce-back response to the proteasome inhibition ${ }^{6,11}$, while multiple other protein groups (Fig. 2A). Genes encoding proteins from these functional groups significantly up- or downregulated in cancer cells found in pathways specific to cancer and common to cancer and multiple myeloma or normal fibroblasts, indicated in Figure 2a, were used as targets in a cancer vulnerability siRNA mini-screen. The choice of particular genes/proteins for the mini-screen was based on the presence in the cancer cells' signature, level change compared to multiple myeloma or normal fibroblasts and the availability of candidate therapeutics for potential repositioning in supplementing the proteasome inhibitor-based therapy (Table S4).

In the screen, the siRNAs targeting the chosen twelve functional protein groups were first used in pairs or trios (Table S4) to compare viability of cancer cell lines to the normal fibroblasts (Fig. 2B, C). The siRNA sets targeting autophagy, molecular chaperones and endocytosis were most significantly decreasing viability of six cancer cell lines of lung, colon and pancreatic cancer upon treatment with carfilzomib - either on average (Fig. 2B) or in the majority of the individual cell lines (Fig. 2C). The same siRNA sets were not decreasing cell viability significantly when supplementing the proteasome inhibition in the normal fibroblasts (Fig. 2B, C). This selected the targeted proteins in autophagy, molecular chaperones and endocytosis pathways the primary candidates for a further testing as vulnerabilities in carfilzomib-treated cancer cells. We then tested how a depletion of these proteins individually affects viability of cancer cells $v s$ normal fibroblasts. HSP70 family proteins HSPA1A/B and HSP40 protein DNAJB1 in molecular chaperones, Cathepsins A and D in autophagy and CHMP5 and RAB11A in endocytosis were the proteins whose depletion most significantly affected the survival of the six tested cancer cell lines in a combination with carfilzomib (Fig. 2D, Fig. 
S2B, C). We concluded that targeting of these proteins and pathways could potentially increase the anti-cancer effect of proteasome inhibition in the therapeutic experimental setups.

\section{Inhibition of HSP70 proteins is efficient in specific killing of cancer cells with the inhibited proteasome}

We tested which of the currently available therapeutic inhibitors targeting autophagy, endocytosis and molecular chaperone pathways are most efficient in killing the cancer cell lines with the inhibited proteasome, in comparison with the normal fibroblasts. Bafilomycicn A1 (the inhibitor of autophagy), Hydroxychloroquine (the drug interfering with autophagy and endocytosis) or 17-AAG (the inhibitor of HSP90 family of molecular chaperones) were all significantly increasing the efficiency of carfilzomib in killing lung, colon and pancreatic cell lines, however they were similarly efficient in killing of the normal cells (Fig. S3A). We then tested three different HSP70 family experimental inhibitors - VER-155008, JG98 and MAL3-101 (Fewell et al., 2004; Li et al., 2013; Massey et al., 2010). The results indicated that while MAL3-101 was toxic to normal fibroblasts, the two former inhibitors, especially VER-155008 at the lower of the used concentrations, were efficient in killing cancer lines and not the normal fibroblasts (Fig. 3A). To confirm this result in a more heterogeneous, patient-derived in vitro model, we used patient-matched tumor/normal organoid culture pairs, five in colon and four in pancreatic cancer (Fig. S3B). Treatment of organoids with combinations of carfilzomib and VER-155008 or JG98 showed that the normal margin tissue from the same individuals is significantly less sensitive to the used drug combinations than the tumor-derived tissue, and confirmed that the use of HSP70 inhibitors is significantly augmenting the carfilzomibdependent decrease of the viability in cancer-derived cells (Fig. 3B, C). A dispersion of organoids' spheroid 3D structures was visible under the combinational treatment only in the cancer organoids when compared to the normal tissue margin-derived organoids (Fig. 3D, e and Fig. S3C). These results prompted us to test the HSP70 inhibitors - VER-155008 or JG98 with carfilzomib in vivo, in subcutaneous xenografts of the cancer cell lines. First, we used colon cancer DLD-1 cell line, where we tested which of the two HSP70 inhibitors was more efficient and less toxic to mice. In this experiment JG98 was less efficient than VER-155008 in increasing carfilzomib's effect on slowing down the xenograft growth (Fig. 3f, g), but it was also notably toxic to the mice - especially in the combination with carfilzomib causing the diarrhea, mouse belly swelling and the body mass decrease (Table S5). VER-155008 both significantly increased the therapeutic effect of carfilzomib and was well tolerated by the animals (Fig. 3F, Fig. S3D, Table S6). The combination of VER-155008 and carfilzomib was also efficient in significantly slowing down the growth of the subcutaneous xenografts derived from the pancreatic cancer PANC-1 cells (Fig. 3H) and the lung cancer H-23 cells (Fig. 3I).

We concluded that the inhibition of HSP70 chaperones, especially with the inhibitor VER155008 , is the effective way of specifically targeting cancer cells with the inhibited proteasome and not the normal cells. This prompted us to further investigate the role of HSP70 proteins in the response to the proteasome inhibition in cancer cells.

\section{High HSP70 level is associated with the resistance to the proteasome inhibition and low proteasome activity in neoplastic cells}

To validate the response of proteins representing pathways important to the survival of the neoplastic cells on the inhibition of the proteasome machinery, we first compared their level changes upon treatment with carfilzomib or siRNA targeting PSMA2 20S proteasome core subunit essential for all the basic proteolytic activates of the 26S proteasome (Walerych et al., 2016). Both carfilzomib and PSMA2 siRNA resulted in the strongest and the most consistent upregulation of HSPA1A/B 
proteins among other molecular chaperones (Fig. 4A, B) chosen from the proteins significantly changing levels in the proteomics analysis and participating in the pathways enriched with the chaperone proteins (Fig. 1G, Fig. 2A, Table S4). Also, none of the tested proteins from the autophagy and endocytosis pathways was upregulated as consistently among the cancer and normal cell lines as HSPA1A/B, on the proteasome inhibition (Fig. S4 A, B).

Multiple myeloma cell lines can be selected to resist the proteasome inhibitors, which is a clinically relevant problem (Murray et al., 2014). We tested if the resistance in H-929 and RPMI-8226 cell lines correlates with the increased basal HSPA1A/B protein levels. Resistant cell lines were obtained by a long-term adaptation to gradually increasing concentrations of carfilzomib starting from $0.1 \mathrm{nM}$. Indeed, the basal and carfilzomib-induced levels of HSPA1A/B in the obtained carfilzomibresistant H-929 and RPMI-8226 cell lines, able to proliferate in up to $18 \mathrm{nM}$ and $24 \mathrm{nM}$ carfilzomib respectively, were higher than in the parental ATCC-derived cells (Fig. 4C, D). Viability of the carfilzomib-resistant cell lines was strongly increased in comparison to the parental cell lines (Fig.4E). This result suggested that in cancer cells, similarly to the carfilzomib-resistant multiple myeloma cells, the constant high level of HSPA1A/B proteins' level may be present. To validate this hypothesis, we analyzed patient-derived tumor and normal tissue margin sample pairs in pancreatic and colon cancers (Fig. S4D). From deep-frozen tissue fragments available in our biobank we chose four sample pairs which upon a protein extraction showed the most significantly higher chymotrypsin-like proteasome activity than the patient-matched normal tissue fragments, and the same number of sample pairs with no significant difference of the proteasome activity in tumor vs. normal tissue ("high" and "low" proteasome activity samples, Fig. 4F). In both - pancreatic and colon tumor tissues - the HSPA1A/B proteins' levels were on average several-fold higher in the samples with the low, than in the samples with the high proteasome activity, while no significant difference was observed in the patient-matched normal tissues (Fig. 4F, G).

The above results validated the proteomics results indicating a strong and consistent increase in HSPA1A/B protein upon the proteasome inhibition and inferred that the high level of HSPA1A/B proteins is an intrinsic attribute of neoplastic cells with a low proteasome activity.

\section{HSPA1A/B is controlled by transcription on the proteasome inhibition and its mRNA level is a risk factor for cancer patients with a low proteasome subunit mRNA level}

To understand how HSPA1A/B level is controlled upon the proteasome inhibition we studied the relation between the proteomes and transcriptomes of the neoplastic cells treated with cafilzomib, We performed a total RNA sequencing in the cancer and multiple myeloma cell lines treated for $24 \mathrm{~h}$ with DMSO (control) and the same carfilzomib concentrations as indicated in Fig. 1E, resulting in $50 \% \pm 10 \%$ decrease in chymotrypsin-like proteasome activity. Hierarchical clustering by Euclidean distance of quantified, protein coding mRNAs (Table S7), showed a similar pattern as in the case of proteomes in Figure 1f, with cancer and multiple myeloma cells clustering separately (Fig. 5A). We performed differential mRNA level analysis between DMSO and carfilzomib-treated samples in all tested cell lines (Table S8). Correlation coefficients by Pearson or Spearman analysis between quantified proteins and protein coding mRNAs of log fold changes in DMSO vs. carfilzomib sample groups (performed only for ID-matched protein-mRNA pairs), averaged in multiple myeloma and cancer cell lines, showed low mRNA-protein change correlation and suggested higher transcriptional control of protein levels in cancer than in multiple myeloma (Fig. S5B). We then matched only significantly up- or downregulated proteins $(\mathrm{p}<0.05)$ to mRNAs in multiple myeloma and cancer cells $(\mathrm{FDR}<0.05)$. This analysis showed that the most proteins significantly changing levels do not match the mRNA significantly changing levels in the same direction, with more proteins upregulated in multiple myeloma than in cancer (Fig. 5B). However, all the major upregulated chaperone proteins 
from HSP90, HSP70, BAG or DNAJA/B families were present among the upregulated proteins direction-matching their significantly upregulated mRNAs in cancer cell lines pooled together (each listed chaperone gene in at least one cancer cell line). Indeed, the HSPA1A/B mRNA levels validated in the cancer cell lines treated with carfilzomib were on average over 30 times increased when compared to DMSO controls (Fig. 5C). Similar, albeit less strong responses, were visible in cases of other carfilzomib-responding molecular chaperones and co-chaperones - HSP90AA1, BAG3 and DNAJB1 (Fig. 5C), which together with earlier proteome-transcriptome changes matching result (Fig. 5B), suggested that proteasome inhibition leads to a general transcriptional induction of molecular chaperones. The main factors controlling molecular chaperone genes' transcription in stress conditions are HSF proteins (Joutsen and Sistonen, 2019). We tested how knock-down of HSF-1 and HSF-2 transcription factors affects the mRNA and protein levels of molecular chaperones and we found that they were downregualted upon concomitant silencing of $H S F 1$ and carfilzomib treatment (Fig. 5C, D) and less significantly upon the silencing of HSF2 (Fig. S5D). The most strongly HSF-1-depedent tested molecular chaperone on proteasome inhibition was HSPA1A/B (Fig. 5C, D). HSF-1 itself was not significantly upregulated in the proteomes of cancer cells treated with carfilzomib (Table S3), while we detected increased HSF-1 phoshporylation in selected cancer cell lines with the inhibited proteasome (Fig. S5D) - the known mechanism of HSF-1 activation in stress conditions (Shah et al., 2016).

Since we found HSPA1A/B to be universally regulated by transcription in tested cancer cells with the inhibited proteasome (Fig. 5B-D), we investigated if HSPA1A/B mRNA level correlates with the proteasome activity and expression of the proteasome subunits. First we used the patient-derived samples from Fig. 4F, with high or low proteasome activates in the pancreatic and colon tumor tissue. While higher mRNA levels of the representative proteasome core subunit genes - PSMA1 or PSMB5 matched the high proteasome activity in the tumor samples (Fig. 5E, Fig. S5E), the HSPA1A gene had a reversed pattern of expression - significantly higher in the low proteasome activity tumor samples (Fig. 5E). This prompted us to test if in publically available datasets of cancer patients the proteasome expression level could affect how the $H S P A 1 A / B$ expression correlates with a patient survival. In the patients with the high PSMA1 expression, which in our tests correlates with the high proteasome activity (Fig. 4E), the high level of HSPA1A expression had less strong influence on the patient survival when compared with the patients with the low $P S M A 1$ expression. In the latter patients, the high HSPA1A expression correlates with a significantly worse prognosis than the low HSPAIA expression - in colon and pancreatic cancers (Fig. 5F), as well as in other cancer types: lung, liver, head/neck, thyroid, ovarian, endometrial and in sarcomas (Fig. S5E).

We concluded that the main molecular chaperones, including HSPA1A/B, are primarily induced by the HSF-1-dependent transcriptional regulation across lung, colon and pancreatic cell lines with the inhibited proteasome. This is in concordance with the association of the high HSPA1A/B mRNA levels with the low proteasome activity which we observed in cancer patient tumor tissues, as well as with the worse prognosis in patients of multiple patient cancer datasets with the low proteasome subunit PSMA1 expression levels.

\section{HSP70 chaperones the $26 \mathrm{~S}$ proteasome and rescues its activity from the carfilzomib inhibition}

Knowing that HSP70 family chaperones HSPA1A/B are strongly induced and important for cancer cells' survival upon the proteasome inhibition (Figs. 1-5), we studied how mechanistically HSPA1A/B affects the processes involved in a protein degradation and a cell survival upon the carfilzomib treatment. First, we tested if HSPA1A/B depletion or overexpression affects directly the activity of the proteasome machinery in cancer and normal fibroblast cells. Chymotrypsin-like proteasome activity decreased insignificantly in control conditions on silencing of $H S P A 1 A / B$ with 
siRNA, while post treatment with carfilzomib the silencing of $H S P A 1 A / B$ caused additional, significant decrease of the proteasome activity compared to the control siRNA, specifically in cancer cells (Fig. 6A). Similar effect was significant in the case of trypsin-like and caspase-like 26S proteasome activities, albeit as expected from previous reports (Kuhn et al., 2007) carfilzomib affected these proteolytic activities less strongly than the chymotrypsin-like activity (Fig. S6A, B). Additionally, treatment with VER-155008 significantly decreased the chymotrypsin-like proteasome activity upon the carfilzomib treatment in cancer cell lines and colon cancer organoids (Fig. S6C, D), while silencing of $H S P 90 A A 1 / B 1$ or DNAJB1 genes had no significant effect (Fig. S6E). We further tested if HSPA1A/B affects the transcriptional bounce-back of the proteasome genes' transcription (Radhakrishnan et al., 2010; Walerych et al., 2016), which could be responsible for the observed effect of HSPA1A/B on the proteasome activity. However, silencing of $H S P A 1 A / B$ did not affect the compensatory bounce-back of two $26 \mathrm{~S}$ proteasome genes representative for this process - PSMA2 and PSMCl (Walerych et al., 2016) - in cancer and normal cell lines (Fig. 6B, Fig. S6F). This suggested that the chaperone activity of HSPA1A/B could be involved in directly affecting the proteasome in cancer cells. To validate this hypothesis we introduced to the study a dominant-negative K71S HSPA1A variant, unable to efficiently bind ATP and thus deprived of the chaperone activity (Newmyer and Schmid, 2001; Walerych et al., 2009). We overexpressed HA-tagged WT or K71S HSPA1A in control conditions and in a silencing-rescue setup - upon $H S P A 1 A / B$ silencing with an siRNA targeting the HSPA1A and HSPA1B mRNA 3'UTRs, in lung cell lines - H-23 and H-1299, suitable for efficient transient co-transfection experiments (Fig. 6C; Fig. S6G). The introduction of K71S HSPA1A in control conditions already affected negatively the chymotrypsin-like proteasome activity and the viability of the cells, while upon the carfilzomib treatment this effect was increased, and the overexpressed WT HSPA1A, but not the K71S variant, rescued the effect of silencing of the endogenous HSPA1A/B (Fig. 6D, e; Fig. S6H, I). This result supported the hypothesis that HSPA1A/B proteins may directly chaperone the $26 \mathrm{~S}$ proteasome. Thus, we performed an immunoprecipitation of the $26 \mathrm{~S}$ proteasome core to detect interacting molecular chaperones. We detected HSPA1A/B but not HSP90AA1 interacting with the proteasome in three cancer cell lines, while in H-23 and PANC-1 cells the binding increased upon the carfilzomib treatment (Fig. 6F). To further validate the hypothesis, we reconstituted an in vitro, ATP-dependent, chaperoning system by using purified human HSPA1A, DNAJ1B and HSP90AA1 proteins and the purified 26S proteasome as the potential chaperone client. The chaperones were first tested for their activity in an in vitro luciferase refolding assay (Walerych et al., 2004a), where the efficient refolding of the heat-inactivated luciferase requires the presence of all HSP70 (in our case - HSPA1A), HSP40 (DNAJB1) and HSP90 (HSP90AA1) active proteins (Fig. S6J). When these chaperones were incubated with the $26 \mathrm{~S}$ proteasome at $37^{\circ} \mathrm{C}$ it turned out that HSPA1A alone, and in the presence of DNAJB1, was significantly increasing the proteasome's chymotrypsin-like activity, while HSP90AA1, DNAJB1 proteins alone or the HSPA1A inactive variant K71S did not have this ability (Fig. 6G). Interestingly, the strongest increase in the proteasome activity was observed when the HSPA1A concentration was decreased and the HSP40 co-chaperone DNAJB1 was present - displaying a pattern of activity known from previous studies, where in the presence of HSP40 increasing of the HSP70 chaperone concentrations resulted in loss of its optimal activity (Moran Luengo et al., 2018). The HSP70-dependent activation effect towards the purified 26S proteasome was inhibited by VER-155008, and the proteasome activity was inhibited by carfilzomib in all the tested conditions (Fig. 6G). However, the proteasome activity remained at significantly higher levels upon carfilzomib treatment in the presence of the HSPA1A-DNAJB1 chaperone setups optimal for supporting of the $26 \mathrm{~S}$ proteasome (Fig. $6 \mathrm{G}$ ). This and the earlier results described in this section indicated that the HSP70 family chaperone proteins HSPA1A/B bind the $26 \mathrm{~S}$ proteasome and decrease the inhibitory efficiency of carfilzomib in vitro and in cancer cells. 


\section{HSPA1A/B contributes to unfolded protein response and autophagy on the proteasome inhibition}

The pathway analysis and the siRNA screen (Fig. 2A-C) and earlier studies indicated that the autophagy and the unfolded protein response (UPR) contribute to resistance of cancer cells to proteasome inhibition. We tested if HSPA1A/B chaperones are involved in those processes in the context of the carfilzomib treatment.

The UPR pathway is an important element of the cellular response to accumulation of unfolded proteins in the ER, also in the presence of proteasome inhibitors (Zulkifli et al., 2021). The main pro-survival UPR pathway is controlled by IRE1 receptor auto-phosphorylation and leads to an increased expression of chaperones and ERAD-related genes (Hetz et al., 2011). To test if HSPA1A/B is involved inactivation of this pathway on proteasome inhibition we analyzed the levels of total and phosphorylated (Ser 724) IRE1 in cancer cell lines transfected with siRNA targeting HSPA1A/B. As expected, treatment of the control cells with carfilzomib resulted in the increased phosphorylation of IRE1 (Fig. 7A). In cells with the silenced $H S P A 1 A / B$ the proteasome inhibitor did not induce the significant increase of phosphorylation of IRE1, measured as a proportion of phos-IRE1 to total IRE1 (Fig. 7B). To confirm the effect of HSPA1A/B on the IRE1 activation we tested its phosphorylation in the presence of VER-155008 alone and in the combination with carfilzomib. In all the tested cell lines the inhibitor of HSP70 significantly blocked the effect of carfilzomib on the increase of phosphorylated IRE1 (Fig. S7A, B).

It is known that the proteasome inhibitors induce macroautophagy in multiple myeloma (Di Lernia et al., 2020) and in cancers (Yao et al., 2012). It was also demonstrated that HSPA1A/B is involved in the regulation of autophagy (Leu et al., 2009; Minoia et al., 2014). To test the role of HSPA1A/B in the regulation of macroautophagy in cancer cell lines with the inhibited proteasome we compared the amount of LC3-II autophagosome marker (Fader and Colombo, 2009) in relation to a housekeeping protein (GAPDH) in the cells transfected with a control or $H S P A 1 A / B$-targeting siRNA and treated subsequently with carfilzomib. We observed that in the cancer cells treated with carfilzomib levels of LC3-II were increased, while the concomitant silencing of $H S P A 1 A / B$ and the inhibition of proteasome resulted in a further, significant accumulation of LC3-II (Fig. 7A, C). Similar effect on the level of LC3-II we found in the same cell lines treated with a combination of carfilzomib and VER-155008 (Fig. 7D). To discriminate if the LC3-II accumulation is a result of an autophagic flux increase or a block in the autophagosome accumulation, we treated the cells on inhibition of HSP70 and/or inhibitition of the proteasome with bafilomicin A1, which blocks lysosome function and their fusion with autophagosomes (Mercer et al., 2021). In the case of carfilzomib and bafilomicin treatment the LC3-II accumulated further compared to carfilzomib alone, indicating an accumulation of autophagosomes and thus - the increase of the autophagic flux. In the case of the additional HSP70 inhibition by VER-155008 the accumulation of LC3-II was not further augmented by bafilomicin (Fig.7D, Fig. S7C, D), indicating that HSP70 is maintaining the increase in an autophagic flux upon the proteasome inhibition.

Since the siRNA mini-screen showed the dependence of the cancer cells viability on lysosomal cathepsins during the proteasome inhibition (Fig. 2), we tested if in this condition HSPA1A/B has an effect on the maturation and activity of the cathepisn D (CTSD). Silencing of $H S P A 1 A / B$ upon the carfilzomib treatment caused decrease in the mature form of CTSD detectable on western-blot (Fig. 7D) and a significant decrease of the CTSD activity (Fig. 7E). This result showed that HSPA1A/B affects the autophagic pathway induced by the proteasome inhibition on multiple stages - the autophagosomes accumulation and the cathepisn D maturation/activity. 
Summarizing - the HSPA1A/B functional effect on cancer cells on carfilzomib treatment extends beyond the direct chaperoning of the 26S proteasome to other processes induced upon the proteasome inhibition specifically in cancer cells - UPR and macroautophagy (Fig. 7G). The inhibitory effect of VER-155008 on these processes helps to interpret the robust and specific anticancer activity of its combination with carfilzomib.

\section{Discussion}

In this study we describe the proteasome inhibition compensatory responses by comparing protein landscape changes in normal fibroblasts, multiple myeloma, colon, lung and pancreatic cancers cells treated with carfilzomib. This approach revealed the general proteasome inhibition response mechanisms, suggested by previous low scale studies - proteasome subunit expression bounce-back (Radhakrishnan et al., 2010; Vangala et al., 2020), autophagy induction (Ding et al., 2007; Zhu et al., 2010) or a molecular chaperone response (Awasthi and Wagner, 2005; Bush et al., 1997; Liao et al., 2006; Minoia et al., 2014), as well as processes responding specifically in each cell type. In cancer cells this included endocytosis, cell motility, mRNA splicing or mitochondrial metabolism. Splicing and the mitochondrial metabolism were previously found as mediators of the proteasome inhibitor resistance in proteomics studies in multiple myeloma cells (Huang et al., 2020a; Soriano et al., 2016). The possibility of comparing different neoplasia types in this study revealed that these processes are even more pronounced in cancer cells.

Our proteomics experiments, unlike ubiquitination-focused studies (Hristova et al., 2020; Wagner et al., 2011) did not discriminate between bona fide proteasome substrates and compensators, and hence we used a vulnerability mini-screen to determine which of the found mechanisms contribute to the compensation of the carfilzomib treatment specifically in cancer cells. The screen found as targetable the compensatory effects of molecular chaperones, autophagy and endocytosis-related proteins. However, the drug tests in cancer cell lines, organoids and in vivo xenografts as well as the low-scale validation - all pointed to the inhibition of HSP70 family proteins as the most cancerspecific, targetable component of the carfilzomib treatment resistance response.

HSPA1A and HSPA1B is a duo of almost identical proteins, sharing a genomic locus (Kudla et al., 2004; Smith et al., 2007), which concomitantly increase levels in response to various stressors, and are functionally interchangeable (Hageman et al., 2011). Therefore we studied them as a single chaperone system in the inhibition/silencing experiments, while we used HSPA1A in the overexpression experiments and as a purified protein. HSPA1A/B along with other molecular chaperones and co-chaperones from HSP70, HSP90, BAG and DNAJ families were reported to be induced on bortezomib teratment with involvement of HSF1 and HSF2 in multiple myeloma, breast and cervical cancers or melanoma (Santopolo et al., 2021; Shah et al., 2015; Shah et al., 2016). We confirm this effect on carfilzomib treatment a in a panel of lung, colon and pancreatic cancer cells by transcriptome-proteasome matching and low-scale validation. Consequently, we found that high levels of HSPA1A mRNA are associated with cancer vs. normal tissue and a bad prognosis in patients of multiple cancer types with a low proteasome subunit expression.

The actual mechanistic purpose of the chaperone response in compensation of the proteasome inhibition has remained vaguely understood. The most often suggested hypothesis has been that the molecular chaperones facilitate folding and clearance of proteins accumulating upon proteasome inhibition, similar to the heat shock conditions (Fernandez-Fernandez et al., 2017; Lee and Goldberg, 1998; Matondo et al., 2017; Tian et al., 2021). While our results are in concordance with such general effects, we show that HSPA1A/B is specifically coordinating multiple independent routes of the proteasome inhibition response in cancer cells. Interestingly, this does not include a support of the 
proteasome subunit gene expression bounce-back, rendering unlikely the HSP70-depedent augmentation of the NRF1/NRF2 activity. In the same time HSP70 affects compensatory processes such as autophagy and unfolded protein response (UPR), shown by us in the siRNA mini-screen and in the functional experiments. These processes were demonstrated in various experimental systems to compensate for the downregulation of the proteasome activity (Ding et al., 2007; Kocaturk and Gozuacik, 2018; Min et al., 2014; Obeng et al., 2006), and selected aspects were shown to be dependent on HSP70 chaperones. For example HSPA1A/B inhibition was shown to induce LC3-II accumulation and impair progress of autophagy in cancer cells (Leu et al., 2009), while in leukemia cells HSPA1A/B downregulation lead to a decrease IRE1, key to one of the main branches of the UPR response (Storniolo et al., 2015). Our study shows that HSPA1A/B inhibition significantly hinders the autophagic flux, maturation of cathepsin D and IRE1 phosphorylation exclusively upon the carfilzomib treatment - significantly decreasing the efficiency of autophagy and UPR response to the proteasome inhibition.

We found that binding and chaperoning of the $26 \mathrm{~S}$ proteasome directly by HSP70 strongly decreases the efficiency of carfilzomib. Earlier, it was shown that individual chaperones may affect the assembly of the 26S proteasome, including HSP90 (Yamano et al., 2008) or HSP70 upon the oxidative stress (Grune et al., 2011), with a HOP co-chaperone optionally involved in linking both systems (Bhattacharya et al., 2020). We demonstrate that the mature 26S proteasome is the HSP70 client, by reconstituting a functional in vitro chaperoning system. In this system HSP70 can be stimulated for optimal efficiency by the HSP40 co-chaperone DNAJB1, while it does not require HSP90 proteins reflected by a lack of HSP90 functional effect and binding to the proteasome in cancer cells. HSP90 often participates in activation of intrinsically unstable substrates in their near-native states (Karagoz et al., 2014) or boosts the HSP70-mediated refolding of stress-unfolded substrates (Moran Luengo et al., 2018). This is a possible cause of the lack of effect of HSP90 on the assembled proteasomes which are relatively stable protein complexes (Hendil et al., 2002; Livneh et al., 2016; Sridharan et al., 2019). On the other hand HSP70-DNAJ chaperone machinery possess HSP90-independent activities, such as a protein disaggregation (Rosenzweig et al., 2019), which could be in effect towards the proteasome in cancer cells. It can be speculated that the stress-induced nature of the HSPA1A/B action towards the proteasome makes its more indispensable in the cancer cells than in the normal fibroblasts (results from Fig. 6A) and allows cancer cells to maintain more proteasome activity under similar viability decrease as in the fibroblasts treated with carfilzomib (results from Fig. 1D). It has been described that an environment of rapidly evolving and proliferating cancer cells is enforcing higher dependence of client proteins on HSP70 and HSP90 chaperone systems (Joshi et al., 2018; Lang et al., 2019) - with the proteasome likely being another such example.

The dependence of the lung, colon and pancreatic cancer cells' survival on the HSP70 chaperones upon the proteasome inhibition opens a largely unexplored therapeutic possibility. Combinations of HSP70 inhibitors with bortezomib were suggested in multiple myeloma (Huang et al., 2020b), melanoma (Yerlikaya et al., 2010) or bladder carcinoma (Qi et al., 2013), however no clinical trials of any of these combinations have been carried out in cancer. Our results in lung, colon and pancreatic cancers suggest that further preclinical and clinical investigations using combination of carfilzomib and HSP70 inhibitors, such as VER-155008, are a justified method in attempt to increase efficacy of treatments in the most deadly cancer types. 


\section{Acknowledgements}

The authors thank prof. Marta Miączyńska of International Institute of Molecular and Cell Biology in Warsaw for critically reading the manuscript, prof. Maciej Żylicz for providing vectors and purified proteins obtained at the Department of Molecular Biology of the International Institute of Molecular and Cell Biology in Warsaw and prof. Cezary Żekanowski for sharing laboratory equipment at the Laboratory of Neurogenetics, Mossakowski Medical Research Institute PAS. We thank all cancer patients from hospitals in Warsaw, Poland, who provided consent to use their tissue samples in the manuscript as a part of the "Multi-onko-mapa" study (109/2016). This research was funded by the National Science Center, Poland grants Opus 2017/25/B/NZ5/01343 (D.W.), Miniatura 2020/04/X/NZ5/01259 (M.O.), as well as EU H2020 Marie Curie Individual Fellowship 795441 (D.W.).

\section{Author contributions}

Conceptualization, D.W., M.O. and M.G.; Methodology, D.W. M.O., M.G, A.J. and J.R.W.; Investigation, D.W. M.O., M.G, A.J., M.C., M.M., K.Z., J.R.W.; Data Curation, D.W. and A.J., Writing - Original Draft, D.W and M.O.; Writing - Review \& Editing, D.W. and M.O.; Funding Acquisition, D.W. and M.O.; Resources, M.N-N., M.K., W.K., T.O. and M.L.; Supervision, D.W.

\section{Declaration of interests}

The authors declare no competing interests. 
bioRxiv preprint doi: https://doi.org/10.1101/2021.11.16.468807; this version posted November 18, 2021. The copyright holder for this preprint (which was not certified by peer review) is the author/funder. All rights reserved. No reuse allowed without permission.

\section{Methods}

\section{RESOURCE AVAILABILITY}

\section{Lead contact}

Further information and requests for resources and reagents should be directed to and will be fulfilled by the lead contact, Dawid Walerych (dwalerych@imdik.pan.pl)

\section{Materials availability}

This study did not generate new unique reagents.

\section{Data and code availability}

The mass spectrometry data have been deposited to the ProteomeXchange Consortium via the PRIDE partner repository with the dataset identifiers PXD025364 (cancer cell lines) and PXD027840 (normal fibroblast cell lines). RNA sequencing data has been deposited in the Gene Expression Omnibus (GEO) under accession code GSE184029.

\section{EXPERIMENTAL MODEL AND SUBJECT DETAILS}

\section{Cell lines}

NCI-H23 (H-23), NCI-H1299 (H-1299), DLD-1 and CAPAN-2 cell lines were cultured in RPMI medium (Gibco) supplemented with 10\% FBS (Gibco) and Pen-Strep antibiotics (Gibco). RKO and PANC-1 cell lines were cultured in DMEM medium (Gibco) supplemented with $10 \%$ FBS and PenStrep antibiotics.

Multiple myeloma cell lines RPMI-8226 and NCI-H929 (H-929) were cultured in suspension, in RPMI medium supplemented with 10\% FBS and Pen-Strep antibiotics (Gibco). Medium for H-929 cells was additionally supplemented with $0,05 \mathrm{mM}$ of 2-mercaptoethanol (Bio-shop).

All the above-mentioned cell lines were acquired commercially from ATCC repository and low passage numbers post acquisition (below 15) were used for the experiments in the manuscript.

Human primary fibroblasts FIB-1 and FIB-2 were cultured in DMEM medium (Gibco) supplemented with 10\% FBS and Pen-Strep antibiotics. Fibroblasts were obtained and characterized at MMRC PAS, Warsaw, from skin biopsies of healthy control subjects, who provided informed consents based on bioethics committee approval 108/2017 and 203/2020 of the Central Clinical Hospital of Ministry of Interior and Administration in Warsaw (Gaweda-Walerych et al., 2021).

All the cell lines were periodically controlled for mycoplasma infection (qPCR, all tests negative throughout the project) and none is present on the v11 of ICLAC register of misidentified cell lines.

\section{Mouse strains and animal care}

NSG/J mice, purchased from The Jackson Laboratory (Bar Harbor, ME, USA), were maintained in an SPF facility under proper environmental conditions $\left(20-24^{\circ} \mathrm{C}\right.$ temperature, $40-60 \%$ humidity, and $12 \mathrm{~h}$ light cycle) with free access to water and food. The core of the breeding colony was a group of sister and brother (female homozygote $\times$ male homozygote) mated animals kept in Maria Sklodowska-Curie National Research Institute of Oncology bank of inbred strains.

\section{Human tissue samples, HE staining and tumor tissue identification}

All experimental procedures using human tissue samples were conducted in accordance with an approval from ethical committee of Central Clinical Hospital of Ministry of Interior and Administration in Warsaw (109/2016 and 128/2018). All patients provided informed consent for the research use of their tissues. Colon cancer and pancreatic cancer tissues and adjacent normal colon and pancreatic tissues were obtained from patients undergoing surgical treatments at the Central Clinical Hospital of the Ministry of Interior and Administration in Warsaw and at the National Institute of Oncology in Warsaw. After preliminary histopathology assessment post-surgery the issue fragments were either frozen and stored in a liquid nitrogen biobank for protein/RNA extraction (see appropriate sections) or kept in a culturing medium at $4^{\circ} \mathrm{C}$ for organoid cultures (see appropriate sections). Further histopathology microscopy assessment was used to confirm presence or absence of cancer tissue in the tissue fragments. Briefly, the tissue material from post-operative specimens was fixed in $10 \%$ buffered 
formalin, the samples were embedded in paraffin, sections of $4 \mu \mathrm{m}$ thickness were stained with haematoxylin and eosin (HE) and observed/photographed using light microscopy. The histological type and the tumour grade were based on the WHO classification. The tumour stage was based upon the 8th edition of AJCC/UICC pTNM.

\section{METHOD DETAILS}

\section{Proteasome activity assay}

Approximately $80 \%$ confluent cells were treated with concentrations of carfilzomib (Selleckchem) as in Fig. 1E unless indicated otherwise in the figures or a corresponding DMSO solvent volume as a control. Cells were washed with PBS, scraped from plates and lysed at $4{ }^{\circ} \mathrm{C}$ in a lysis buffer containing $1 \% \mathrm{NP}-40,150 \mathrm{mM} \mathrm{NaCl}, 50 \mathrm{mM}$ Tris- $\mathrm{HCl}$ at $\mathrm{pH} 8$, and the cell remains were spun down. In the case of tissue samples, homogenization was performed using protein extraction beads (Diagenode) and sonication in the lysis buffer followed by centrifugation to remove solid remains (Diagenode Bioruptor Plus sonicator manufacturer's protocol for protein extraction from tissue fragments). $50 \mu \mathrm{g}$ of total protein extract was used per one measurement. Protein extracts in equal volumes were resuspended in $1 \mathrm{x}$ assay buffer containing $25 \mathrm{mM}$ HEPES $\mathrm{pH} 7.5,0.5 \mathrm{mM}$ EDTA, $0.05 \%$ NP-40, $0.001 \%$ SDS to the volume of $90 \mu \mathrm{l}$ per measurement and supplemented with $10 \mu 1$ of $0.5 \mathrm{mM}$ proteasome substrates in the assay buffer: Substrate III (Suc-LLVY-AMC, chymotrypsin-like activity, Millipore), Substrate IV (Z-ARR-AMC, trypsin-like activity, Enzo) and Substrate II (Z-LLE-AMC, caspase-like activity, Enzo). Samples with substrates in 96-well black plates were incubated at $37^{\circ} \mathrm{C}$ for $2 \mathrm{~h}$ and measured using Tecan M1000 plate spectrofluorometer. Controls, sensitivity calibration and standard curves were made on the basis of recommendations of the 20S Proteasome Activity Assay Kit (Millipore).

\section{Cathepsin D activity assay}

Cells were washed with PBS, scraped from plates and lysed at $4^{\circ} \mathrm{C}$ in a lysis buffer containing $1 \%$ $\mathrm{NP}-40,150 \mathrm{mM} \mathrm{NaCl}, 50 \mathrm{mM}$ Tris- $\mathrm{HCl}$ at $\mathrm{pH}$ 8, and the cell remains were spun down. $20 \mu \mathrm{g}$ of total protein extract was used per one measurement. Protein extracts in equal volumes were resuspended in $1 \mathrm{x}$ assay buffer containing: HEPES $20 \mathrm{mM} \mathrm{pH} 4, \mathrm{MgCl} 21 \mathrm{mM}, \mathrm{KOAc} 137 \mathrm{mM}, \mathrm{NaCl} 50 \mathrm{mM}$, K2HPO4 50mM, EDTA $2 \mathrm{mM}$, DTT $2 \mathrm{mM}$ to the volume of $90 \mu \mathrm{l}$ per measurement and supplemented with $10 \mu \mathrm{l}$ of $0.1 \mathrm{mM}$ cathepsin D fluorogenic substrate in assay buffer (Enzo). Samples with substrates in 96 -well black plates were incubated at $37^{\circ} \mathrm{C}$ for $1 \mathrm{~h}$ and measured using Tecan M1000 plate spectrofluorometer.

\section{Viability assays and drug tests}

Cells were plated in 96-well white plates with clear bottom at 50\% confluence for siRNA transfection (see 'siRNA screen' section for details) or $70 \%$ confluence for drugs test. VER-155008, hydroxychloroqiune, bafilomycin A (Tocris), MAL3-101 (A ChemTek, Inc), JG-98, 17-AAG, carfilzomib (Selleckchem) stock solutions were prepared in DMSO. The fresh medium with drugs at the concentrations indicated in the figures or DMSO solvent was added $24 \mathrm{~h}$ and $48 \mathrm{~h}$ after seeding. The viability was measured with ATPlite One Step reagent (Perkin Elmer) after $48 \mathrm{~h}$ of the treatment. The results were reconfirmed with resazurin assay. The $10 \mu \mathrm{l}$ of resazurin solution in PBS $(0.1 \mathrm{mg} / \mathrm{ml})$ was added directly to the cells growing in $200 \mu \mathrm{l}$ of culture medium and incubated for $3 \mathrm{~h}$ in cell culture incubator. Afterward the fluorescence was measured (Ex/Em 530-560/590 nm) using Tecan M1000 plate spectrofluorometer.

\section{Proteomics analysis}

Cells were lysed in 50mM Tris-HCl, pH 7.8 buffer containing 1\% (w/v) SDS and $0.1 \mathrm{M}$ dithiothreitol, sonicated until the lysates were clear of long DNA and other visible cell debris (Diagenode Bioruptor Plus sonicator). Lysates were processed by the Multi-Enzyme Digestion Filter Aided Sample Preparation (MED FASP) protocol (Wisniewski and Mann, 2012) with minor modifications (Walerych et al., 2016). Briefly, proteins were digested overnight with endoproteinase LysC and then with trypsin for $3 \mathrm{~h}$. The enzyme to protein ratio was 1:50. The total protein and peptide concentrations were determined by WF-assay (Wisniewski and Gaugaz, 2015). Aliquots containing $0.5 \mu \mathrm{g}$ peptides were separated on a reverse phase C18 column and were analyzed on QExactive HF 
Mass Spectrometer (Thermo-Fisher Scientific) as described previously (Wisniewski and Zettl, 2019). Spectra were searched by MaxQuant software (https://maxquant.net/maxquant/) and the concentrations of proteins were assessed by the total protein approach using the raw protein intensities (Wisniewski, 2017b). Perseus software (https://maxquant.net/perseus/) was used to perform differential analysis, $\mathrm{t}$-tests and assess $\mathrm{p}$-value support of differences between protein concentrations in distinct experimental conditions.

\section{Pathway analysis}

Proteins significantly changing levels $(\mathrm{p}<0.05)$ in the proteomics differential analysis in cancer, multiple myeloma and normal fibroblast cell lines were each fused in to signatures and filtered for duplicates. Such signatures were used in ClueGO ver. 2.5.8 (Bindea et al., 2009) plug-in in Cytoscape ver. 3.8.2 (www.cytoscape.org) to associate proteins with molecular pathways. ClueGO settings were: All_Experimental evidence, GO Molecular Pathways/KEGG/WikiPathways ontologies, network specificity slider half way between Medium and Detailed settings, show only pathways with $\mathrm{pV}<0.05$. Analyses performed for the separate - cancer, multiple myeloma and normal fibroblast signatures were exported into tables and overlapped (Table S4) to determine pathways specific and common to the signatures. The graph in Fig. 2A was generated by performing the ClueGO pathway association with the same settings as above, using all three signatures as separate marker lists, and further node color/shape/link refinement in the Cytoscape environment according to signature overlap results in Table S4.

Ingenuity Pathway Analysis (IPA, Qiagen) was done by using protein lists significantly changing levels in each cell line ( $<<0.05$ in the proteomics differential analysis) to perform core analyses. Results for canonical pathways were then overlapped in IPA separately for cancer, multiple myeloma and normal fibroblast cell lines and the overlaps were compared to find common and specific pathways to each cell line type.

\section{Plasmids}

N-terminally HA-tagged WT and K71S HSP70 pCDNA 3.1 vectors were generated by cloning and subsequent site-directed mutagenesis at the Department of Molecular Biology at the International Institute of Molecular and Cell Biology in Warsaw (Walerych et al., 2009). Expression vectors for chaperone protein overexpression in E.coli purification are described in the protein purification section.

\section{siRNA screen}

siRNAs were purchased from QIAgen or Sigma Aldrich (company-validated, pre-designed sequences). Cells were plated in 96-well plates (white, transparent bottom) and transfected 2x at $0 \mathrm{~h}$ and $24 \mathrm{~h}$ with $20 \mathrm{nM}$ of siRNA (mixes or single) with GenMute transfection reagent (SignaGen) in cancer cell lines or Lipofectamine RNAiMAX (Invitrogen) in fibroblasts as in the manufacturer's instructions. $48 \mathrm{~h}$ after second transfection cells were treated with Carfilzomib or DMSO. Viability was measured after further $24 \mathrm{~h}$ using ATPlite OneStep reagent (Perkin Elmer), according to the manufacturer's instructions. The list of siRNAs is provided in the Table S8.

\section{Transfection}

For siRNA transfections outside of the siRNA screen, all cells lines were transfected $2 \mathrm{x}$ at $0 \mathrm{~h}$ and $24 \mathrm{~h}$ with $20 \mathrm{nM}$ of indicated siRNAs using Lipofectamine RNAiMax (Invitrogen). After $24 \mathrm{~h}$ post the second silencing, cells were processed. siRNA sequences are listed in Table S8.

H-1299 and H-23 cells were transfected with plasmids or co-transfected with plasmids and siRNAs using Lipofectamine 2000 (Invitrogen) as in the manufacturer's instructions.

\section{Total RNA extraction and RT-qPCR}

Total RNA was extracted from cell lines with QIAzol (Qiagen) following the manufacturer's instructions, and form frozen tissue fragments - using QIAzol (Qiagen), RNA extraction beads (Diagenode) in a Diagenode Bioruptor Plus sonicator, according to a manufacturer's RNA extraction protocol. RNA concentrations and quality was controlled using a NanoDrop spectrophotometer (Thermo). $1 \mu \mathrm{g}$ microgram of total RNA was reverse-transcribed with NG dART RT kit (EURx). 
qPCR was performed using Sensitive RT HS-PCR Mix SYBR (A\&A Biotechnology) on One Step Plus Real-Time PCR System (Applied Biosystems). The list of qPCR primers is provided in Table S8.

\section{RNA-sequencing}

The cells were treated for $24 \mathrm{~h}$ with Carfilzomib concentrations identical as for proteomics procedures in Fig.1E. Total RNA was extracted with QIAzol (Qiagen) following the manufacturer's instructions, RNA quality was controlled using NanoDrop (Thermo) and RNA analyzer Experion (Biorad). Additional RNA quality check, library preparation (TruSeq Stranded TotalRNA, Illumina), sequencing (2x $100 \mathrm{bp}, 100 \mathrm{M}$ reads; NovaSeq6000) and preliminary data quality check and analysis was performed by $\mathrm{CeGaT} \mathrm{GmbH}$. Quality assessment of the raw data including filtering and trimming was carried out using FastQC_v.0.11.9 (http://www.bioinformatics.babraham.ac.uk/projects/fastqc/) and the data was further processed using tool Trimmomatic_v.0.36 (http://www.usadellab.org/cms/?page=trimmomatic) for removal of low quality reads (phred-score $\leq$ 20 and length $30 \mathrm{bp}$, singletons discarded, reads with ambiguous bases ' $\mathrm{N}$ '), trimming of bases from $5, / 3$ ' end and adaptor sequences. Refined and filtered reads were further mapped to the reference human genome by Bowtie2 - used for indexing (http://bowtie-bio.sourceforge.net/bowtie2/), and HISAT2 - used for mapping (http://daehwankimlab.github.io/hisat2/). The successfully mapped reads were further processed to FeaturesCount $\mathrm{R}$ package to calculate the abundance of each transcript and extract quality score of mapped reads. Good quality scores were saved in a matrix form and were used as an input for determination of differentially expressed genes between control (DMSO) and carfilzomib treatment conditions by using DESeq2. The Relative Log Expression (RLE) method was used in DESeq2 to calculate normalization factors. Benjamini and Hochberg false discovery rate, FDR $<0.05$ was considered as statistically significant parameter of significantly differentially expressed genes. The count matrix genes were annotated with Ensembl BioMart to extract protein coding genes, which were used to generate principal component analysis (PCA) plot.

\section{Western blot analysis}

Cell were lysed in a mild lysis buffer $(150 \mathrm{mM} \mathrm{NaCl}, 1 \%$ NP-40, 50mM HEPES pH 8.0) supplemented with a HALT protease inhibitor cocktail (Thermo). Protein concentrations were determined using WF-assay (Wisniewski and Gaugaz, 2015). Lysates were incubated at $95^{\circ} \mathrm{C}$ in a Laemmli Sample Buffer, required protein amounts resolved by SDS-PAGE and transferred to nitrocellulose membrane (Millipore). Western blot analysis was performed according to standard procedures, using $5 \%$ fat-free milk in TBS-Tween $200.1 \%$ to block and wash the membranes. The densitometry on WB bands was performed using ImageJ. The antibodies and concentrations used for WB are listed in Table S8.

\section{Human colon cancer and normal colon organoid cultures}

Colon cancer and normal colon tissues were transported at $4^{\circ} \mathrm{C}$ in culturing medium w/o growth factors and processed within $18 \mathrm{~h}$ from resections. Protocol from (Sato et al., 2011) with small modifications was used to generate colon organoids. First, tissues were washed 10 times with ice-cold PBS, then minced using surgical scalpel. Minced tissues were incubated in digestion medium (Collagenase type II $5 \mathrm{mg} / \mathrm{ml}$ [GIBCO], Dispase $5 \mathrm{mg} / \mathrm{ml}$ [GIBCO], Y-27632 $10.5 \mu \mathrm{M}$ [Sigma], DNase I $10 \mu \mathrm{g} / \mathrm{ml}$ [Sigma], Advanced DMEM/F12 [GIBCO], HEPES $10 \mathrm{mM}$ pH 7.5 [Invitrogen], GlutaMAX Supplement 1x [Invitrogen], Primocin $100 \mathrm{ug} / \mathrm{ml}$ [InvivoGen], Bovine Serum Albumin $0.1 \%$ [Sigma]) for 40 minutes at $37^{\circ} \mathrm{C}$ with rotation. Remaining undigested tissue fragments were allowed to settle to the bottom of the tube for 1 minute, then the supernatant was collected in a $15 \mathrm{ml}$ Falcon tube, centrifuged at $300 \mathrm{RCF}$ for 5 minutes at $4^{\circ} \mathrm{C}$. The cell pellet was embedded in a growth factor reduced Matrigel (Corning) or Cultrex Basement Membrane Extract type 2 (R\&Dsystems). After 20 minutes incubation at $37^{\circ} \mathrm{C}$, matrigel domes were covered with the culturing medium (Advanced DMEM/F12 [GIBCO], HEPES $10 \mathrm{mM} \mathrm{pH} 7.5$ [Invitrogen], GlutaMAX Supplement 1x [Invitrogen], 10\% R-spondin-1 conditioned medium (Ootani et al., 2009), 50\% Wnt-3A conditioned medium (Sato et al., 2011), N-acetylcysteine $1.25 \mathrm{mM}$ [Sigma], Nicotinamide $10 \mathrm{mM}$ [Sigma], B27 supplement 1x [GIBCO], Primocine $100 \mathrm{ug} / \mathrm{ml}$ [InvivoGen], murine Noggin $100 \mathrm{ng} / \mathrm{ml}$ [Peprotech], human EGF $50 \mathrm{ng} / \mathrm{ml}$ [Peprotech], human Gastrin I $10 \mathrm{nM}$ [Tocris], Prostaglandin E2 10nM [Tocris], A83-01 $500 \mathrm{nM}$ [Tocris], Y-27632 $10.5 \mathrm{uM}$ [Sigma], SB202190 3 uM [Sigma]). 
bioRxiv preprint doi: https://doi.org/10.1101/2021.11.16.468807; this version posted November 18, 2021. The copyright holder for this preprint (which was not certified by peer review) is the author/funder. All rights reserved. No reuse allowed without permission.

\section{Human pancreatic cancer and normal pancreatic organoid cultures}

Pancreatic organoids were generated in a similar way to colon organoids based on (Boj et al., 2016), with addition of human FGF-10 $100 \mathrm{ng} / \mathrm{ml}$ (Peprotech) and no SB202190 in the culturing medium. Prostaglandin E2 10nM (Tocris) was added only to medium for normal tissue organoids.

\section{Drug sensitivity assays in cell lines and organoids}

Cell lines were treated by adding the drugs (or their solvents in equal volumes) at concentrations indicated in the figures to the standard growth media. Viability assay was performed after indicated time periods.

For organoids 96-well plates with clear bottom and white walls were used for testing. $33 \mu 1$ of Matrigel or Basement Membrane Extract type 2 were added to each well. Plates were then centrifuged at $1000 \mathrm{RCF}$ for 1 minute and placed in a $37^{\circ} \mathrm{C}, 5 \% \mathrm{CO}_{2}$ incubator for 30 minutes. To each well a $100 \mathrm{ul}$ suspension of approximately 500 organoids in the culturing medium were added. Organoids were left for $24 \mathrm{~h}$ in a $37^{\circ} \mathrm{C}, 5 \% \mathrm{CO}_{2}$ incubator. Afterwards the drugs were added in the culturing medium. Organoids plates were incubated with drugs for $24 \mathrm{~h}$, then cell viability was measured using ATPlite Luminescence Assay (PerkinElmer).

\section{Immunofluorescence staining of human colon and pancreatic organoids}

Organoids cultured in a chamber slide (Ibidi) and incubated for $24 \mathrm{~h}$ with the indicated drugs, were fixed with 4\% PFA for 20 minutes, washed with PBS/Glycine solution, permeabilized with $0.5 \%$ TritonX-100/PBS for 10 minutes and blocked with 3\% bovine serum albumin/PBS. Incubation with a primary antibody was done overnight at $4^{\circ} \mathrm{C}$. Primary antibodies used: E-Cadherin (Cell Signaling Technology, 24E10) and Laminin-5 (Santa Cruz Biotechnology, P3H9-2). Incubation with a secondary antibody was done overnight at $4^{\circ} \mathrm{C}$. Secondary antibodies used: Alexa Fluor 488 (Life Technologies, A11001) and Alexa Fluor 555 (Life Technologies, A21428). Incubation with $0.5 \mathrm{ng} / \mathrm{ml}$ DAPI in PBS for 10 minutes was used for staining of nuclei. Image acquisition was performed using Carl Zeiss LSM 780 confocal microscope.

\section{Kaplan-Meier estimator analysis}

The analysis was performed in the KM-plotter (kmplot.com) using the mRNA gene-chip data for lung cancer and the pan-cancer RNA-seq data for other cancer types shown in the figures. The multiple genes option was used to filter the results by a median of PSMA1 expression (above/below median high/low expression) and patients survival was further stratified according to HSPAlA high/low expression. The log-rank test and hazard ratio (HR) estimation were performed by the KM-plotter tool to assess the effect of gene expression on the patient survival.

\section{Co-immunoprecipitation}

Selected cell lines were treated with carfilzomib or DMSO as for proteomics analysis. After $24 \mathrm{~h}$ formaldehyde cross-linking was performed according to the protocol from (Klockenbusch and Kast, 2010). Briefly, cells were treated with $0.4 \%$ formaldehyde solution in PBS for 7 minutes at room temperature $\left(1 \mathrm{ml}\right.$ of formaldehyde solution per $1 \times 10^{\wedge} 7$ cells). Cells were then pelleted at $1800 \mathrm{RCF}$ for 3 minutes at room temperature. Cell pellet was resuspended in $0.5 \mathrm{ml}$ ice-cold $1.25 \mathrm{M}$ glycine/PBS and centrifuged at $1800 \mathrm{RCF}$ for 3 minutes at $4^{\circ} \mathrm{C}$. Cells were lysed $(150 \mathrm{mM} \mathrm{NaCl}, 50 \mathrm{mM}$ Tris-HCl $\mathrm{pH} 7.4, \mathrm{NP} 401 \%$ and protease inhibitors [Thermo]) and immunoprecipitation was performed overnight at $4{ }^{\circ} \mathrm{C}$ using Proteasome $20 \mathrm{~S}$ core subunits polyclonal antibody (ENZO Life Sciences BMLPW8155) and IP buffer (137 mM NaCl, $50 \mathrm{mM}$ Tris-HCl pH 7.4, NP40 1\%, 2 mM EDTA pH 8 and $10 \%$ glycerol). Immunopellets were washed 3 times with the IP buffer without glycerol, and boiled in the 1x Laemmli sample buffer for 15 minutes. SDS-PAGE and western blot was performed. Detection of Hsp70, Hsp90 and 20S Proteasome was done using primary antibodies: HSP70 (ENZO Life Sciences, ADI-SPA-812-F), HSP90 (Cell Signalling, C45G5) and PSMA2 (Cell Signaling, 2455S). TidyBlot:HRP conjugated Western Blot Detection Reagent (Bio-Rad) was used in accordance with manufacturer's protocol as the secondary antibody.

Protein purification, luciferase refolding assay and in vitro 26S proteasome chaperoning reaction Human HSPA1A (Hsp70) WT and K71S, HSP90AA1 (Hsp90 $\alpha$ ), DNAJB1 (Hdj1) were purified and tested by a luciferase refolding assay as described previously (Walerych et al., 2004b; Walerych et al., 
2009). Human $26 \mathrm{~S}$ proteasome purified from HEK293 cells was purchased from Promega. The proteasome chaperoning reaction tests were carried out as follows: $5 \mathrm{nM}$ of the purified proteasome and the molecular chaperone proteins (or a mass equivalent of BSA as the control) in concentrations indicated in the figure were added on ice to a final reaction volume of $10 \mu 1$ with the reaction buffer containing: $10 \mathrm{mM}$ Tris- $\mathrm{HCl} \mathrm{pH}$ 7.5, $50 \mathrm{mM} \mathrm{KCl}, 3 \mathrm{mM} \mathrm{MgCl} 2,2 \mathrm{mM}$ DTT, $5 \mathrm{mM}$ ATP, ATPregeneration system ( 0.3 units of creatine kinase, $150 \mathrm{mM}$ of phosphocreatine; Roche) and optionally: DMSO (drug solvent control), carfilzomib or VER-155008. The reaction mixes were incubated for 30' at $37^{\circ} \mathrm{C}$. The proteasome activity assay followed by addition to each mix of $80 \mu \mathrm{l}$ of the $1 \mathrm{x}$ assay buffer $+10 \mu 1$ of $0.5 \mathrm{mM}$ proteasome chymotrypsin-like proteasome activity substrate and incubation for $1 \mathrm{~h}$ at $37^{\circ} \mathrm{C}$ in a 96 -well black plate before fluorescence measurements (see the Proteasome activity assay section).

\section{In vivo xenograft experiments}

Experiments were carried out in the animal facilities of Maria Sklodowska-Curie National Research Institute of Oncology, in accordance with the protocols approved by the Second Local Ethics Committee for Animal Experimentation in Warsaw (decision no. WAW2/117/2020).

Xenograft implantations were performed on 6-18 week-old mice in a separate operating room using aseptic procedures. To induce subcutaneous xenografts from cultured cell lines, $2 \times 10^{6}$ of cancer cells (DLD-1, H-23 and PANC-1) suspended in 100 $\mu$ l PBS were injected subcutaneously into a flank of eight animals per group. Tumor diameters were measured weekly with a caliper until reaching a volume of $100 \mathrm{~mm}^{3}$, calculated using the following formula: (length $\times$ width $\times$ width) $/ 2$.

\section{Animal groups and drug administration}

When all the tumors within a set exceeded the required volume the animals were assigned randomly to treated and control groups. Experiment 1, DLD-1: 7 x 6 animals; DMSO - control group, carfilzomib CFZ (Selleckchem, $4 \mathrm{mg} / \mathrm{kg}$ ), VER-155008 (Tocris, $35 \mathrm{mg} / \mathrm{kg}$ ), JG98 (Selleckchem, $4 \mathrm{mg} / \mathrm{kg}$ ), VER+CFZ (35 mg/kg $+4 \mathrm{mg} / \mathrm{kg})$, JG98+CFZ (4 mg/kg $+4 \mathrm{mg} / \mathrm{kg})$, were diluted in $200 \mu 1 \mathrm{PBS}-$ $5 \%$ Tween- 80 and injected intraperitoneally every other day. Experiment 2 and 3, PANC-1 2x7 animals and H-23 2x5 animals: DMSO - control group, VER+CFZ (35 mg/kg $+4 \mathrm{mg} / \mathrm{kg})$. Mice were carefully observed for the appearance of signs of distress. Tumor diameters were measured every third or fourth day with a caliper. On day 21 or when a tumor volume exceed $1500 \mathrm{~mm} 3$, mice within a set were sacrificed. Blood was collected, and tumors were excised for histopathological and molecular examinations.

\section{QUANTIFICATION AND STATISTICAL ANALYSIS}

All data are represented as mean \pm standard deviation (SD) or standard error of the mean (SEM). Figure legends contain information on independent biological replicates and statistical tests used. The statistical analysis was performed using GraphPad Prism 8.0.2. Proteomics, RNAseq and Pathway analysis sections contain details on statistical analysis used in large-scale and pathway analysis procedures. 
bioRxiv preprint doi: https://doi.org/10.1101/2021.11.16.468807; this version posted November 18, 2021. The copyright holder for this preprint (which was not certified by peer review) is the author/funder. All rights reserved. No reuse allowed without permission.

\section{References:}

Arastu-Kapur, S., Anderl, J. L., Kraus, M., Parlati, F., Shenk, K. D., Lee, S. J., Muchamuel, T., Bennett, M. K., Driessen, C., Ball, A. J., and Kirk, C. J. (2011). Nonproteasomal targets of the proteasome inhibitors bortezomib and carfilzomib: a link to clinical adverse events. Clin Cancer Res $17,2734-2743$.

Awasthi, N., and Wagner, B. J. (2005). Upregulation of heat shock protein expression by proteasome inhibition: an antiapoptotic mechanism in the lens. Invest Ophthalmol Vis Sci 46, 2082-2091.

Belalcazar, A., Shaib, W. L., Farren, M. R., Zhang, C., Chen, Z., Yang, L., Lesinski, G. B., El-Rayes, B. F., and Nagaraju, G. P. (2017). Inhibiting heat shock protein 90 and the ubiquitin-proteasome pathway impairs metabolic homeostasis and leads to cell death in human pancreatic cancer cells. Cancer 123, 4924-4933.

Berenson, J. R., Hilger, J. D., Yellin, O., Dichmann, R., Patel-Donnelly, D., Boccia, R. V., Bessudo, A., Stampleman, L., Gravenor, D., Eshaghian, S., et al. (2014). Replacement of bortezomib with carfilzomib for multiple myeloma patients progressing from bortezomib combination therapy. Leukemia 28, 1529-1536.

Bhattacharya, K., Weidenauer, L., Luengo, T. M., Pieters, E. C., Echeverria, P. C., Bernasconi, L., Wider, D., Sadian, Y., Koopman, M. B., Villemin, M., et al. (2020). The Hsp70-Hsp90 co-chaperone Hop/Stip1 shifts the proteostatic balance from folding towards degradation. Nat Commun 11, 5975.

Bindea, G., Mlecnik, B., Hackl, H., Charoentong, P., Tosolini, M., Kirilovsky, A., Fridman, W. H., Pages, F., Trajanoski, Z., and Galon, J. (2009). ClueGO: a Cytoscape plug-in to decipher functionally grouped gene ontology and pathway annotation networks. Bioinformatics 25, 1091-1093.

Boj, S. F., Hwang, C. I., Baker, L. A., Engle, D. D., Tuveson, D. A., and Clevers, H. (2016). Model organoids provide new research opportunities for ductal pancreatic cancer. Molecular \& cellular oncology 3 , e1014757.

Borjan, B., Kern, J., Steiner, N., Gunsilius, E., Wolf, D., and Untergasser, G. (2019). Spliced XBP1 Levels Determine Sensitivity of Multiple Myeloma Cells to Proteasome Inhibitor Bortezomib Independent of the Unfolded Protein Response Mediator GRP78. Front Oncol 9, 1530.

Bush, K. T., Goldberg, A. L., and Nigam, S. K. (1997). Proteasome inhibition leads to a heat-shock response, induction of endoplasmic reticulum chaperones, and thermotolerance. The Journal of biological chemistry $272,9086-9092$.

Chen, Y., Zhang, Y., and Guo, X. (2017). Proteasome dysregulation in human cancer: implications for clinical therapies. Cancer metastasis reviews 36, 703-716.

Collins, G. A., and Goldberg, A. L. (2017). The Logic of the 26S Proteasome. Cell 169, 792-806.

Di Lernia, G., Leone, P., Solimando, A. G., Buonavoglia, A., Saltarella, I., Ria, R., Ditonno, P., Silvestris, N., Crudele, L., Vacca, A., and Racanelli, V. (2020). Bortezomib Treatment Modulates Autophagy in Multiple Myeloma. Journal of clinical medicine 9.

Ding, W. X., Ni, H. M., Gao, W., Yoshimori, T., Stolz, D. B., Ron, D., and Yin, X. M. (2007). Linking of autophagy to ubiquitin-proteasome system is important for the regulation of endoplasmic reticulum stress and cell viability. Am J Pathol 171, 513-524.

Fader, C. M., and Colombo, M. I. (2009). Autophagy and multivesicular bodies: two closely related partners. Cell death and differentiation 16, 70-78. 
bioRxiv preprint doi: https://doi.org/10.1101/2021.11.16.468807; this version posted November 18, 2021. The copyright holder for this preprint (which was not certified by peer review) is the author/funder. All rights reserved. No reuse allowed without permission.

Fernandez-Fernandez, M. R., Gragera, M., Ochoa-Ibarrola, L., Quintana-Gallardo, L., and Valpuesta, J. M. (2017). Hsp70 - a master regulator in protein degradation. FEBS Lett 591, 2648-2660.

Fewell, S. W., Smith, C. M., Lyon, M. A., Dumitrescu, T. P., Wipf, P., Day, B. W., and Brodsky, J. L. (2004). Small molecule modulators of endogenous and co-chaperone-stimulated Hsp70 ATPase activity. The Journal of biological chemistry 279, 51131-51140.

Gaweda-Walerych, K., Walerych, D., Berdynski, M., Buratti, E., and Zekanowski, C. (2021). Parkin Levels Decrease in Fibroblasts With Progranulin (PGRN) Pathogenic Variants and in a Cellular Model of PGRN Deficiency. Front Mol Neurosci 14, 676478.

Groen, K., van de Donk, N., Stege, C., Zweegman, S., and Nijhof, I. S. (2019). Carfilzomib for relapsed and refractory multiple myeloma. Cancer Manag Res 11, 2663-2675.

Grune, T., Catalgol, B., Licht, A., Ermak, G., Pickering, A. M., Ngo, J. K., and Davies, K. J. (2011). HSP70 mediates dissociation and reassociation of the 26S proteasome during adaptation to oxidative stress. Free Radic Biol Med 51, 1355-1364.

Hageman, J., van Waarde, M. A., Zylicz, A., Walerych, D., and Kampinga, H. H. (2011). The diverse members of the mammalian HSP70 machine show distinct chaperone-like activities. Biochem J 435, 127-142.

Hendil, K. B., Hartmann-Petersen, R., and Tanaka, K. (2002). $26 \mathrm{~S}$ proteasomes function as stable entities. J Mol Biol 315, 627-636.

Hetz, C., Martinon, F., Rodriguez, D., and Glimcher, L. H. (2011). The unfolded protein response: integrating stress signals through the stress sensor IRE1alpha. Physiological reviews 91, 1219-1243.

Hristova, V., Sun, S., Zhang, H., and Chan, D. W. (2020). Proteomic analysis of degradation ubiquitin signaling by ubiquitin occupancy changes responding to $26 \mathrm{~S}$ proteasome inhibition. Clin Proteomics $17,2$.

Huang, H. H., Ferguson, I. D., Thornton, A. M., Bastola, P., Lam, C., Lin, Y. T., Choudhry, P., Mariano, M. C., Marcoulis, M. D., Teo, C. F., et al. (2020a). Proteasome inhibitor-induced modulation reveals the spliceosome as a specific therapeutic vulnerability in multiple myeloma. Nat Commun 11, 1931.

Huang, L., Wang, Y., Bai, J., Yang, Y., Wang, F., Feng, Y., Zhang, R., Li, F., Zhang, P., Lv, N., et al. (2020b). Blockade of HSP70 by VER-155008 synergistically enhances bortezomib-induced cytotoxicity in multiple myeloma. Cell stress \& chaperones 25, 357-367.

Huang, Z., Wu, Y., Zhou, X., Xu, J., Zhu, W., Shu, Y., and Liu, P. (2014). Efficacy of therapy with bortezomib in solid tumors: a review based on 32 clinical trials. Future oncology 10, 1795-1807.

Hui, B., Shi, Y. H., Ding, Z. B., Zhou, J., Gu, C. Y., Peng, Y. F., Yang, H., Liu, W. R., Shi, G. M., and Fan, J. (2012). Proteasome inhibitor interacts synergistically with autophagy inhibitor to suppress proliferation and induce apoptosis in hepatocellular carcinoma. Cancer 118, 5560-5571.

Joshi, S., Wang, T., Araujo, T. L. S., Sharma, S., Brodsky, J. L., and Chiosis, G. (2018). Adapting to stress - chaperome networks in cancer. Nat Rev Cancer 18, 562-575.

Joutsen, J., and Sistonen, L. (2019). Tailoring of Proteostasis Networks with Heat Shock Factors. Cold Spring Harbor perspectives in biology 11 .

Karagoz, G. E., Duarte, A. M., Akoury, E., Ippel, H., Biernat, J., Moran Luengo, T., Radli, M., Didenko, T., Nordhues, B. A., Veprintsev, D. B., et al. (2014). Hsp90-Tau complex reveals molecular basis for specificity in chaperone action. Cell 156, 963-974. 
bioRxiv preprint doi: https://doi.org/10.1101/2021.11.16.468807; this version posted November 18, 2021. The copyright holder for this preprint (which was not certified by peer review) is the author/funder. All rights reserved. No reuse allowed without permission.

Kisselev, A. F., Akopian, T. N., Castillo, V., and Goldberg, A. L. (1999). Proteasome active sites allosterically regulate each other, suggesting a cyclical bite-chew mechanism for protein breakdown. Molecular cell 4, 395-402.

Klockenbusch, C., and Kast, J. (2010). Optimization of formaldehyde cross-linking for protein interaction analysis of non-tagged integrin beta1. J Biomed Biotechnol 2010, 927585.

Kocaturk, N. M., and Gozuacik, D. (2018). Crosstalk Between Mammalian Autophagy and the Ubiquitin-Proteasome System. Front Cell Dev Biol 6, 128.

Kudla, G., Helwak, A., and Lipinski, L. (2004). Gene conversion and GC-content evolution in mammalian Hsp70. Mol Biol Evol 21, 1438-1444.

Kuhn, D. J., Chen, Q., Voorhees, P. M., Strader, J. S., Shenk, K. D., Sun, C. M., Demo, S. D., Bennett, M. K., van Leeuwen, F. W., Chanan-Khan, A. A., and Orlowski, R. Z. (2007). Potent activity of carfilzomib, a novel, irreversible inhibitor of the ubiquitin-proteasome pathway, against preclinical models of multiple myeloma. Blood 110, 3281-3290.

Kumar Deshmukh, F., Yaffe, D., Olshina, M. A., Ben-Nissan, G., and Sharon, M. (2019). The Contribution of the 20S Proteasome to Proteostasis. Biomolecules 9.

Lang, B. J., Guerrero-Gimenez, M. E., Prince, T. L., Ackerman, A., Bonorino, C., and Calderwood, S. K. (2019). Heat Shock Proteins Are Essential Components in Transformation and Tumor Progression: Cancer Cell Intrinsic Pathways and Beyond. Int J Mol Sci 20.

Lee, D. H., and Goldberg, A. L. (1998). Proteasome inhibitors cause induction of heat shock proteins and trehalose, which together confer thermotolerance in Saccharomyces cerevisiae. Mol Cell Biol 18, $30-38$.

Leu, J. I., Pimkina, J., Frank, A., Murphy, M. E., and George, D. L. (2009). A small molecule inhibitor of inducible heat shock protein 70. Molecular cell 36, 15-27.

Li, X., Srinivasan, S. R., Connarn, J., Ahmad, A., Young, Z. T., Kabza, A. M., Zuiderweg, E. R., Sun, D., and Gestwicki, J. E. (2013). Analogs of the Allosteric Heat Shock Protein 70 (Hsp70) Inhibitor, MKT-077, as Anti-Cancer Agents. ACS Med Chem Lett 4.

Li, X., Zhu, F., Jiang, J., Sun, C., Zhong, Q., Shen, M., Wang, X., Tian, R., Shi, C., Xu, M., et al. (2016). Simultaneous inhibition of the ubiquitin-proteasome system and autophagy enhances apoptosis induced by ER stress aggravators in human pancreatic cancer cells. Autophagy 12, 1521-1537.

Liao, W., Li, X., Mancini, M., and Chan, L. (2006). Proteasome inhibition induces differential heat shock protein response but not unfolded protein response in HepG2 cells. J Cell Biochem 99, 10851095.

Livneh, I., Cohen-Kaplan, V., Cohen-Rosenzweig, C., Avni, N., and Ciechanover, A. (2016). The life cycle of the $26 \mathrm{~S}$ proteasome: from birth, through regulation and function, and onto its death. Cell Res $26,869-885$.

Manasanch, E. E., and Orlowski, R. Z. (2017). Proteasome inhibitors in cancer therapy. Nat Rev Clin Oncol 14, 417-433.

Massey, A. J., Williamson, D. S., Browne, H., Murray, J. B., Dokurno, P., Shaw, T., Macias, A. T., Daniels, Z., Geoffroy, S., Dopson, M., et al. (2010). A novel, small molecule inhibitor of Hsc70/Hsp70 potentiates Hsp90 inhibitor induced apoptosis in HCT116 colon carcinoma cells. Cancer chemotherapy and pharmacology 66, 535-545.

Matondo, M., Marcellin, M., Chaoui, K., Bousquet-Dubouch, M. P., Gonzalez-de-Peredo, A., Monsarrat, B., and Burlet-Schiltz, O. (2017). Determination of differentially regulated proteins upon 
proteasome inhibition in AML cell lines by the combination of large-scale and targeted quantitative proteomics. Proteomics 17.

Mercer, T. J., Ohashi, Y., Boeing, S., Jefferies, H. B. J., De Tito, S., Flynn, H., Tremel, S., Zhang, W., Wirth, M., Frith, D., et al. (2021). Phosphoproteomic identification of ULK substrates reveals VPS15dependent ULK/VPS34 interplay in the regulation of autophagy. Embo J 40, e105985.

Min, H., Xu, M., Chen, Z. R., Zhou, J. D., Huang, M., Zheng, K., and Zou, X. P. (2014). Bortezomib induces protective autophagy through AMP-activated protein kinase activation in cultured pancreatic and colorectal cancer cells. Cancer chemotherapy and pharmacology 74, 167-176.

Minoia, M., Boncoraglio, A., Vinet, J., Morelli, F. F., Brunsting, J. F., Poletti, A., Krom, S., Reits, E., Kampinga, H. H., and Carra, S. (2014). BAG3 induces the sequestration of proteasomal clients into cytoplasmic puncta: implications for a proteasome-to-autophagy switch. Autophagy 10, 1603-1621.

Moran Luengo, T., Kityk, R., Mayer, M. P., and Rudiger, S. G. D. (2018). Hsp90 Breaks the Deadlock of the Hsp70 Chaperone System. Molecular cell 70, 545-552 e549.

Murata, S., Takahama, Y., Kasahara, M., and Tanaka, K. (2018). The immunoproteasome and thymoproteasome: functions, evolution and human disease. Nat Immunol 19, 923-931.

Murray, M. Y., Auger, M. J., and Bowles, K. M. (2014). Overcoming bortezomib resistance in multiple myeloma. Biochemical Society transactions 42, 804-808.

Newmyer, S. L., and Schmid, S. L. (2001). Dominant-interfering Hsc70 mutants disrupt multiple stages of the clathrin-coated vesicle cycle in vivo. J Cell Biol 152, 607-620.

Obeng, E. A., Carlson, L. M., Gutman, D. M., Harrington, W. J., Jr., Lee, K. P., and Boise, L. H. (2006). Proteasome inhibitors induce a terminal unfolded protein response in multiple myeloma cells. Blood 107, 4907-4916.

Ootani, A., Li, X., Sangiorgi, E., Ho, Q. T., Ueno, H., Toda, S., Sugihara, H., Fujimoto, K., Weissman, I. L., Capecchi, M. R., and Kuo, C. J. (2009). Sustained in vitro intestinal epithelial culture within a Wnt-dependent stem cell niche. Nat Med 15, 701-706.

Qi, W., White, M. C., Choi, W., Guo, C., Dinney, C., McConkey, D. J., and Siefker-Radtke, A. (2013). Inhibition of inducible heat shock protein-70 (hsp72) enhances bortezomib-induced cell death in human bladder cancer cells. PLoS One 8 , e69509.

Quante, A. S., Ming, C., Rottmann, M., Engel, J., Boeck, S., Heinemann, V., Westphalen, C. B., and Strauch, K. (2016). Projections of cancer incidence and cancer-related deaths in Germany by 2020 and 2030. Cancer Med 5, 2649-2656.

Radhakrishnan, S. K., Lee, C. S., Young, P., Beskow, A., Chan, J. Y., and Deshaies, R. J. (2010). Transcription factor Nrf1 mediates the proteasome recovery pathway after proteasome inhibition in mammalian cells. Molecular cell 38, 17-28.

Rahib, L., Wehner, M. R., Matrisian, L. M., and Nead, K. T. (2021). Estimated Projection of US Cancer Incidence and Death to 2040. JAMA Netw Open 4, e214708.

Rosenzweig, R., Nillegoda, N. B., Mayer, M. P., and Bukau, B. (2019). The Hsp70 chaperone network. Nat Rev Mol Cell Biol 20, 665-680.

Rousseau, A., and Bertolotti, A. (2018). Regulation of proteasome assembly and activity in health and disease. Nat Rev Mol Cell Biol 19, 697-712.

Santopolo, S., Riccio, A., Rossi, A., and Santoro, M. G. (2021). The proteostasis guardian HSF1 directs the transcription of its paralog and interactor HSF2 during proteasome dysfunction. Cell Mol Life Sci 78, 1113-1129. 
bioRxiv preprint doi: https://doi.org/10.1101/2021.11.16.468807; this version posted November 18, 2021. The copyright holder for this preprint (which was not certified by peer review) is the author/funder. All rights reserved. No reuse allowed without permission.

Sato, T., Stange, D. E., Ferrante, M., Vries, R. G., Van Es, J. H., Van den Brink, S., Van Houdt, W. J., Pronk, A., Van Gorp, J., Siersema, P. D., and Clevers, H. (2011). Long-term expansion of epithelial organoids from human colon, adenoma, adenocarcinoma, and Barrett's epithelium. Gastroenterology $141,1762-1772$.

Shah, S. P., Lonial, S., and Boise, L. H. (2015). When Cancer Fights Back: Multiple Myeloma, Proteasome Inhibition, and the Heat-Shock Response. Mol Cancer Res 13, 1163-1173.

Shah, S. P., Nooka, A. K., Jaye, D. L., Bahlis, N. J., Lonial, S., and Boise, L. H. (2016). Bortezomibinduced heat shock response protects multiple myeloma cells and is activated by heat shock factor 1 serine 326 phosphorylation. Oncotarget 7, 59727-59741.

Smith, R. S., Meyers, D. A., Peters, S. P., Moore, W. C., Wenzel, S. A., Bleecker, E. R., and Hawkins, G. A. (2007). Sequence analysis of HSPA1A and HSPA1B in a multi-ethnic study population. DNA sequence : the journal of DNA sequencing and mapping $18,47-53$.

Soriano, G. P., Besse, L., Li, N., Kraus, M., Besse, A., Meeuwenoord, N., Bader, J., Everts, B., den Dulk, H., Overkleeft, H. S., et al. (2016). Proteasome inhibitor-adapted myeloma cells are largely independent from proteasome activity and show complex proteomic changes, in particular in redox and energy metabolism. Leukemia 30, 2198-2207.

Sridharan, S., Kurzawa, N., Werner, T., Gunthner, I., Helm, D., Huber, W., Bantscheff, M., and Savitski, M. M. (2019). Proteome-wide solubility and thermal stability profiling reveals distinct regulatory roles for ATP. Nat Commun 10, 1155.

Storniolo, A., Raciti, M., Cucina, A., Bizzarri, M., and Di Renzo, L. (2015). Quercetin affects Hsp70/IRE1alpha mediated protection from death induced by endoplasmic reticulum stress. Oxid Med Cell Longev 2015, 645157.

Teicher, B. A., and Tomaszewski, J. E. (2015). Proteasome inhibitors. Biochem Pharmacol 96, 1-9.

Tian, G., Hu, C., Yun, Y., Yang, W., Dubiel, W., Cheng, Y., and Wolf, D. A. (2021). Dual roles of HSP70 chaperone HSPA1 in quality control of nascent and newly synthesized proteins. Embo J 40, e106183.

Tsvetkov, P., Adler, J., Myers, N., Biran, A., Reuven, N., and Shaul, Y. (2018). Oncogenic addiction to high $26 \mathrm{~S}$ proteasome level. Cell death $\&$ disease 9,773 .

Vandewynckel, Y. P., Coucke, C., Laukens, D., Devisscher, L., Paridaens, A., Bogaerts, E., Vandierendonck, A., Raevens, S., Verhelst, X., Van Steenkiste, C., et al. (2016). Next-generation proteasome inhibitor oprozomib synergizes with modulators of the unfolded protein response to suppress hepatocellular carcinoma. Oncotarget 7, 34988-35000.

Vangala, J. R., Potluri, A., and Radhakrishnan, S. K. (2020). BET Inhibitors Synergize with Carfilzomib to Induce Cell Death in Cancer Cells via Impairing Nrf1 Transcriptional Activity and Exacerbating the Unfolded Protein Response. Biomolecules 10.

Wagner, S. A., Beli, P., Weinert, B. T., Nielsen, M. L., Cox, J., Mann, M., and Choudhary, C. (2011). A proteome-wide, quantitative survey of in vivo ubiquitylation sites reveals widespread regulatory roles. Mol Cell Proteomics 10, M111 013284.

Walerych, D., Kudla, G., Gutkowska, M., Wawrzynow, B., Muller, L., King, F. W., Helwak, A., Boros, J., Zylicz, A., and Zylicz, M. (2004a). Hsp90 chaperones wild-type p53 tumor suppressor protein. Journal of Biological Chemistry 279, 48836-48845.

Walerych, D., Kudla, G., Gutkowska, M., Wawrzynow, B., Muller, L., King, F. W., Helwak, A., Boros, J., Zylicz, A., and Zylicz, M. (2004b). Hsp90 chaperones wild-type p53 tumor suppressor protein. J Biol Chem 279, 48836-48845. 
Walerych, D., Lisek, K., Sommaggio, R., Piazza, S., Ciani, Y., Dalla, E., Rajkowska, K., GawedaWalerych, K., Ingallina, E., Tonelli, C., et al. (2016). Proteasome machinery is instrumental in a common gain-of-function program of the p53 missense mutants in cancer. Nat Cell Biol 18, 897-909.

Walerych, D., Olszewski, M. B., Gutkowska, M., Helwak, A., Zylicz, M., and Zylicz, A. (2009). Hsp70 molecular chaperones are required to support p53 tumor suppressor activity under stress conditions. Oncogene 28, 4284-4294.

Wisniewski, J. R. (2017a). Label-Free and Standard-Free Absolute Quantitative Proteomics Using the "Total Protein" and "Proteomic Ruler" Approaches. Methods Enzymol 585, 49-60.

Wisniewski, J. R. (2017b). Label-Free Quantitative Analysis of Mitochondrial Proteomes Using the Multienzyme Digestion-Filter Aided Sample Preparation (MED-FASP) and "Total Protein Approach". Methods Mol Biol 1567, 69-77.

Wisniewski, J. R., and Gaugaz, F. Z. (2015). Fast and sensitive total protein and Peptide assays for proteomic analysis. Anal Chem 87, 4110-4116.

Wisniewski, J. R., and Mann, M. (2012). Consecutive proteolytic digestion in an enzyme reactor increases depth of proteomic and phosphoproteomic analysis. Anal Chem 84, 2631-2637.

Wisniewski, J. R., Wegler, C., and Artursson, P. (2019). Multiple-Enzyme-Digestion Strategy Improves Accuracy and Sensitivity of Label- and Standard-Free Absolute Quantification to a Level That Is Achievable by Analysis with Stable Isotope-Labeled Standard Spiking. J Proteome Res 18, 217-224.

Wisniewski, J. R., and Zettl, K. (2019). Datasets: Sensitivity and protein digestion course of proteomic Filter Aided Sample Preparation. Data in brief 26, 104530.

Yamano, T., Mizukami, S., Murata, S., Chiba, T., Tanaka, K., and Udono, H. (2008). Hsp90-mediated assembly of the $26 \mathrm{~S}$ proteasome is involved in major histocompatibility complex class I antigen processing. The Journal of biological chemistry 283, 28060-28065.

Yao, F., Wang, G., Wei, W., Tu, Y., Tong, H., and Sun, S. (2012). An autophagy inhibitor enhances the inhibition of cell proliferation induced by a proteasome inhibitor in MCF-7 cells. Molecular medicine reports $5,84-88$.

Yerlikaya, A., Okur, E., Eker, S., and Erin, N. (2010). Combined effects of the proteasome inhibitor bortezomib and Hsp70 inhibitors on the B16F10 melanoma cell line. Molecular medicine reports 3, 333-339.

Zhu, K., Dunner, K., Jr., and McConkey, D. J. (2010). Proteasome inhibitors activate autophagy as a cytoprotective response in human prostate cancer cells. Oncogene 29, 451-462.

Zulkifli, A., Tan, F. H., Areeb, Z., Stuart, S. F., Gomez, J., Paradiso, L., and Luwor, R. B. (2021). Carfilzomib Promotes the Unfolded Protein Response and Apoptosis in Cetuximab-Resistant Colorectal Cancer. Int J Mol Sci 22. 
bioRxiv preprint doi: https://doi.org/10.1101/2021.11.16.468807; this version posted November 18, 2021. The copyright holder for this preprint (which was not certified by peer review) is the author/funder. All rights reserved. No reuse allowed without permission.

Figure 1

A

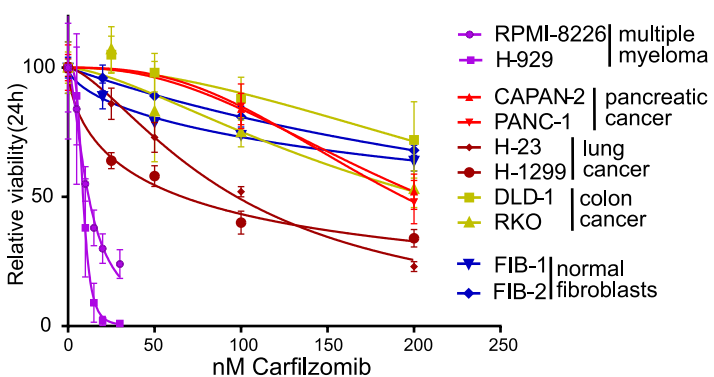

B

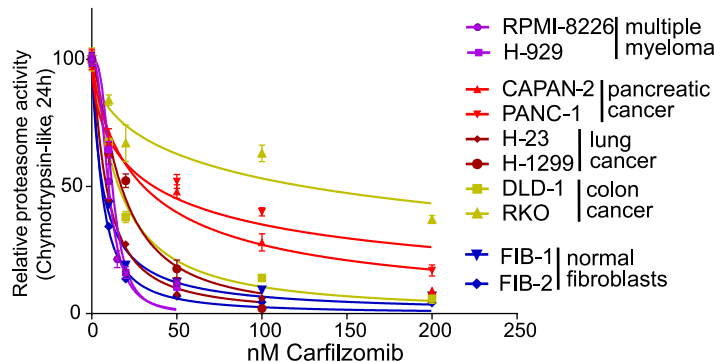

C

Viability at carfilzomib IC50 of proteasome activity

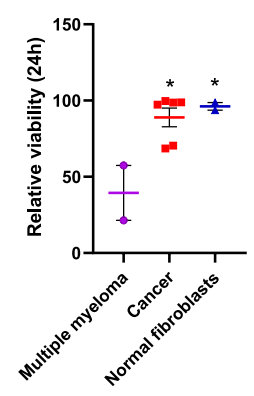

D

Proteasome activity at carfilzomib IC50 of viability
$\mathrm{E}$

Proteomics experimental scheme:

CFZ concentrations proteasome activity at 24h):

Cell lines: at 24h):

RPMI-8226 $15 \mathrm{nM}$ :

CAPAN-2 $40 \mathrm{nM} \quad$ (2 repl. CFZ

$\begin{array}{lll}\text { PANC-1 } & 50 \mathrm{nM} & \text { vs } 2 \text { repl. } \\ \text { DMSO) }\end{array}$

$\mathrm{H}-23 \quad 10 \mathrm{nM}$

DLD-1 $20 \mathrm{nM}$

RKO $\quad 120 \mathrm{nM}$

$\begin{array}{ll}\text { FIB-1 } & 10 \mathrm{nM} \\ \text { FIB-2 } & 10 \mathrm{nM}\end{array}$

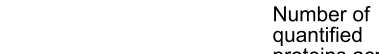

MED-FASP 4 cell line samples:

sample Protein RPMI-8226-7558 Number of

preparation
(LysC/Trypisn andification quantification H-929-7644 $\begin{aligned} & \text { common } \\ & \text { quantified }\end{aligned}$

digestion) $\begin{gathered}\text { (total protein } \\ \text { approach) }\end{gathered}$

Label -free PANC-1 - 7623

LC-MS/MS

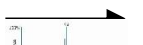

H-1299- 7782

H-1299- 7782

4137

RKO - 7697

FIB-1 - 5238
FIB-2 - 5358

$\mathrm{F}$

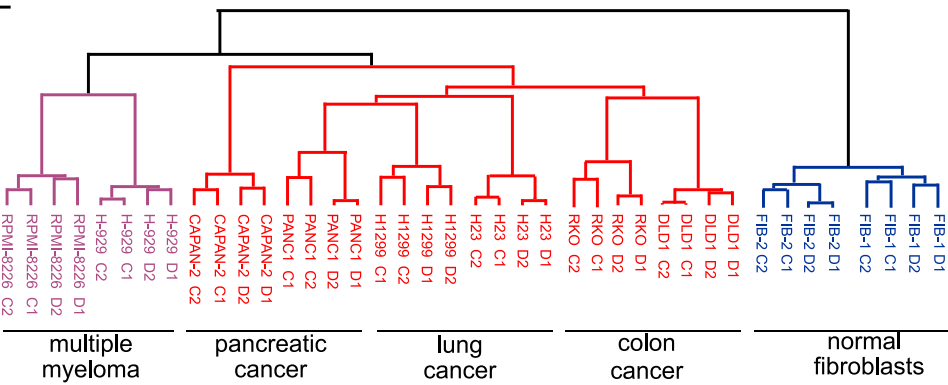

G

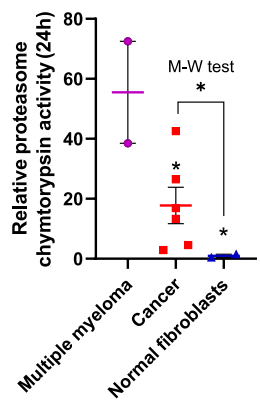

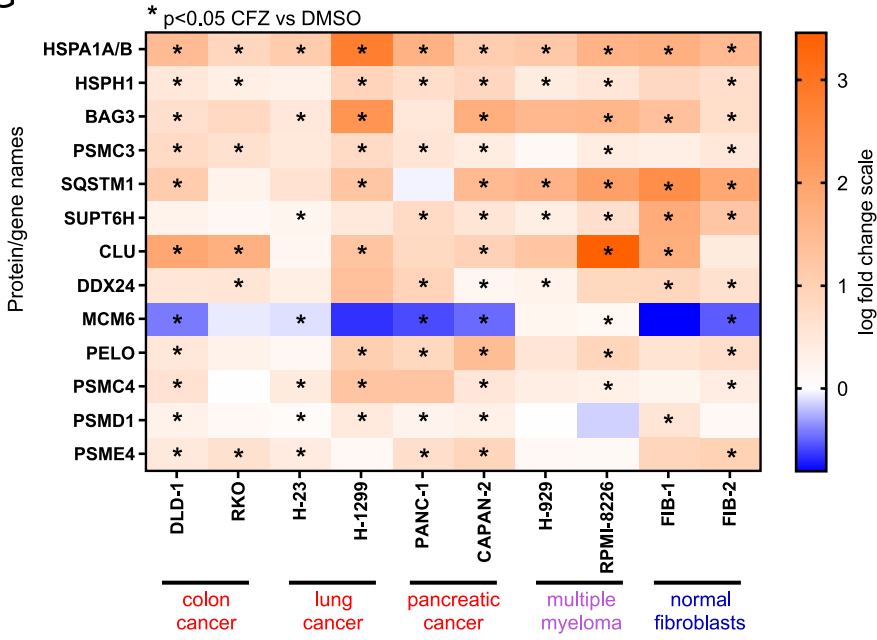


Figure 1 Differences and similarities of cancer, multiple myeloma and normal fibroblast cells response to the proteasome inhibition.

A, Indicated cell lines were treated with increasing concentrations of Carfilzomib for 24h, their viability was measured by the ATP-lite assay (Methods) and normalized results plotted against the used Carfilzomib concentrations (means of $n=3$, with $\mathrm{SD}$ ), with nonlinear least-squares regression curves fitted to the data points.

B, Indicated cell lines were treated with increasing concentrations of Carfilzomib for $24 \mathrm{~h}$, and their chymotrypsin-like proteasome activity was measured (Methods) and normalized results plotted against the used Carfilzomib concentrations (means of $n=3$, with SD), with nonlinear least-squares regression curves fitted to the data points.

C, Differences in viability of indicated cell line groups calculated at Carfilzomib IC50 of the proteasome activity from B (details in Table S1). Means with SEM, one-way ANOVA with Dunnett's correction, ${ }^{*} \mathrm{p}<0.05$.

D, Differences in chymotrypsin-like proteasome activity of indicated cell line groups calculated at Carfilzomib IC50 of the viability form A (details in Table S1). Means with SEM, one-way ANOVA with Dunnett's correction, $* \mathrm{p}<0.05$. For cancer vs. multiple myeloma cells Mann-Whitney test was additionally performed $-* \mathrm{p}<0.05$.

E, Scheme of proteomics experiments performed using samples from shown cell lines treated with indicated carfilzomib concentrations (for $50 \% \pm 10 \%$ proteasome activity) and listed numbers of quantified proteins.

F, Hierarchical clustering (Euclidean distance) of proteomics results for 4137 proteins quantified in each of 40 proteomes from 10 cell lines (i.e. proteins not quantified in any of the 40 samples were not considered).

G, Heat map of log fold changes in differential protein level analysis between CFZ (carfilzomib treated) and DMSO (control) in proteomes of indicated cell lines. Proteins with t-test $p$-value $<0.05$ significant result are marked with *. Only proteins with six or more significant results are shown. Full result available in Table S3. 
bioRxiv preprint doi: https://doi.org/10.1101/2021.11.16.468807; this version posted November 18, 2021. The copyright holder for this Figure 2 preprint (which was not certified by peer review) is the author/funder. All rights reserved. No reuse allowed without permission.
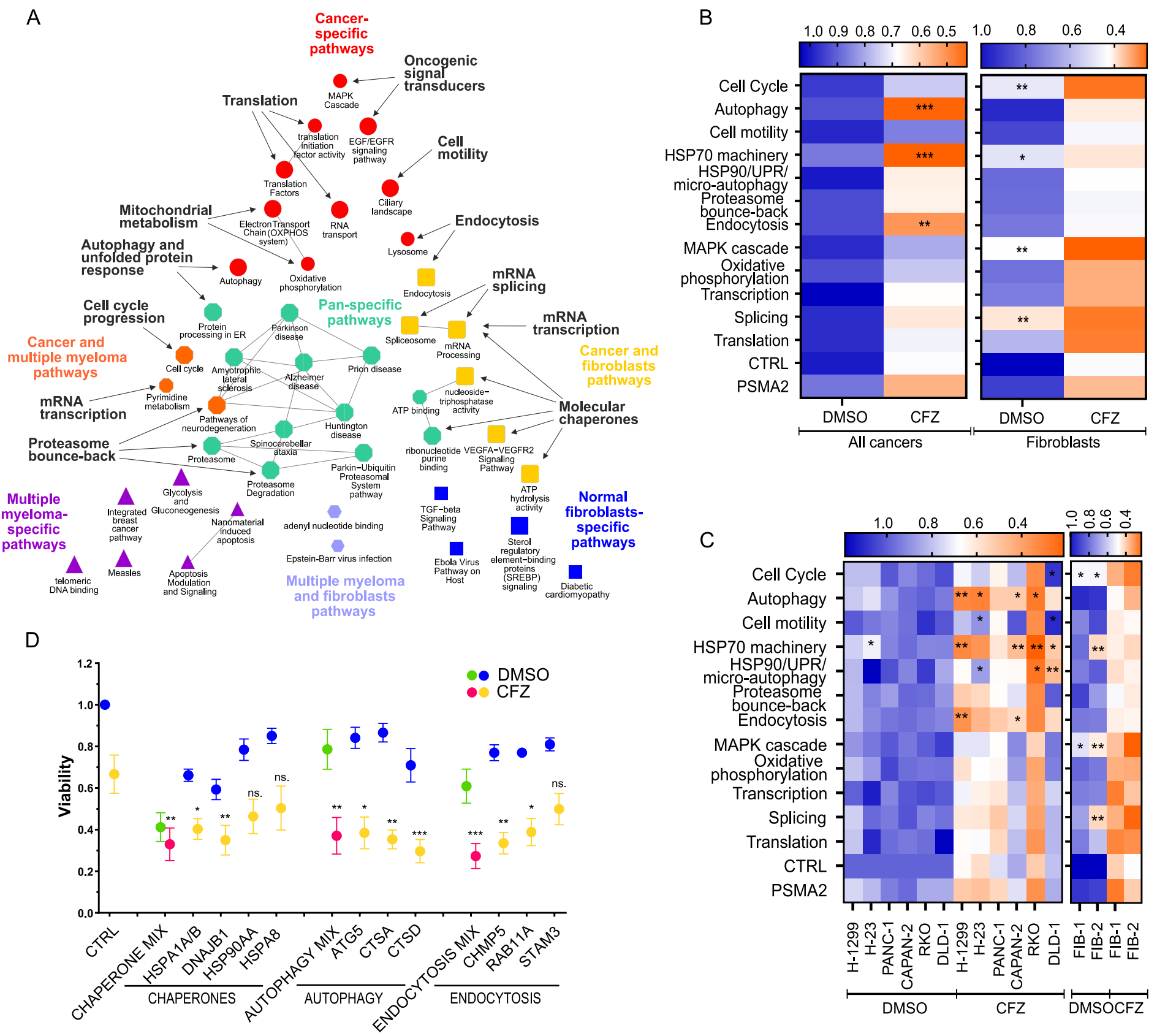
Figure 2 Molecular pathways involving molecular chaperones, autophagy, and endocytosis-related genes contribute to cancer cells' resistance to carfilzomib.

A, Cytoscape-generated ClueGO analysis of molecular pathways regulated by carfilzomib treatment (pathways association FDR $<0.05$, larger symbol size FDR $<0.01$ ), based on the proteomics data in Fig. 1. Colors, shapes and colored captions represent molecular pathways specific to cancer (red), normal fibroblast (dark blue), and multiple myeloma (magenta) cell lines, pathways common to two of them (dark yellow, orange and light blue), or all studied cell types (light green). Black captions show functional gene/protein groups represented in the pathways (indicated with arrows), selected for siRNA vulnerability mini-screen. See Table S4 for details.

B, C, Cancer cells and normal fibroblasts were transfected with a mixture of two siRNAs targeting genes within the indicated functional groups (all gene names listed in the Table S4) and treated with carfilzomib (CFZ) or vehicle (DMSO). siRNA targeting PSMA2 gene served as a control targeting directly the proteasome bounce-back response. Viability was measured $24 \mathrm{~h}$ after treatment using the ATP-lite luminescence assay (Methods). Panel B shows mean values for all tested cancer and normal fibroblast cell lines, panel $\mathbf{C}$ presents the viability of individual cell lines. Data in the heat map in $\mathbf{B}$ are means of $\mathrm{n}=6$ for cancer and $\mathrm{n}=2$ for normal fibroblasts, in $\mathbf{C}$ are means of $\mathrm{n}=2$ for each indicated cell line. Two-way ANOVA with Dunnett's correction of DMSO samples vs the DMSO the treated siRNA negative control CFZ-treated siRNA negative control (CTRL): ${ }^{*} p<0.05,{ }^{* *} p<0.01,{ }^{* * *} p<$ 0.001 .

D, Viability of the cancer cells transfected with an indicated combination or individual siRNAs targeting genes in the functional groups performing best in siRNA mini-screen $(\mathrm{B}, \mathrm{C})$ - molecular chaperones, autophagy or endocytosis - treated with CFZ or DMSO for 48h. Mix of siRNAs contains all 3 or 4 siRNAs used separately within a given functional group. Data points are means of $n=6$ cancer cell lines, error bars represent SEM. Two-way ANOVA with Dunnett's correction for the siRNA vs. the CFZ-treated siRNA negative control (CTRL) ${ }^{*} p<0.05, * * p<0.01, * * * p<0.001$. 
bioRxiv preprint doi: https://doi.org/10.1101/2021.11.16.468807; this version posted November 18, 2021. The copyright holder for this preprint (which was not certified by peer review) is the author/funder. All rights reserved. No reuse allowed without permission.

Figrure 3

A

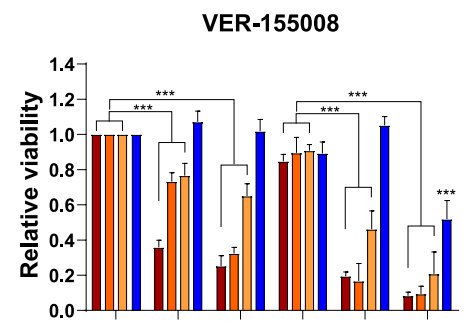

JG98

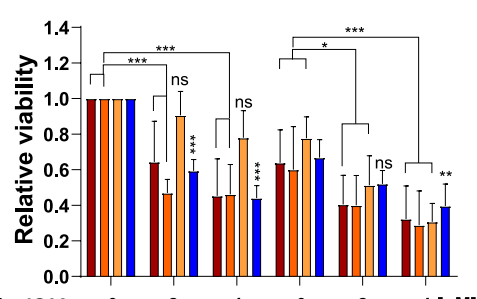

MAL3-101

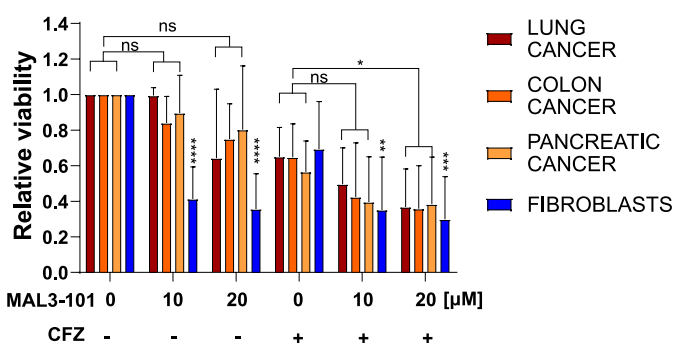

B

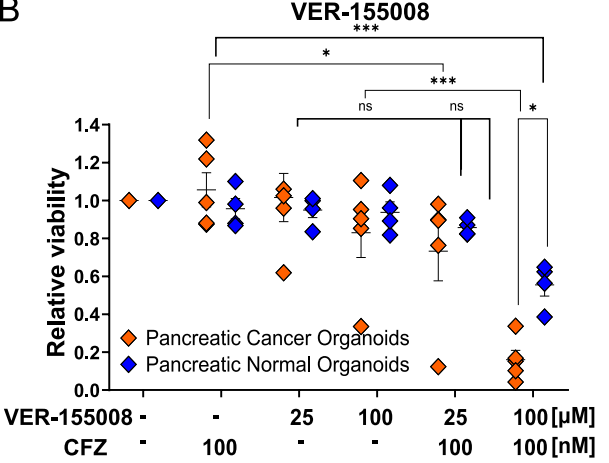

C
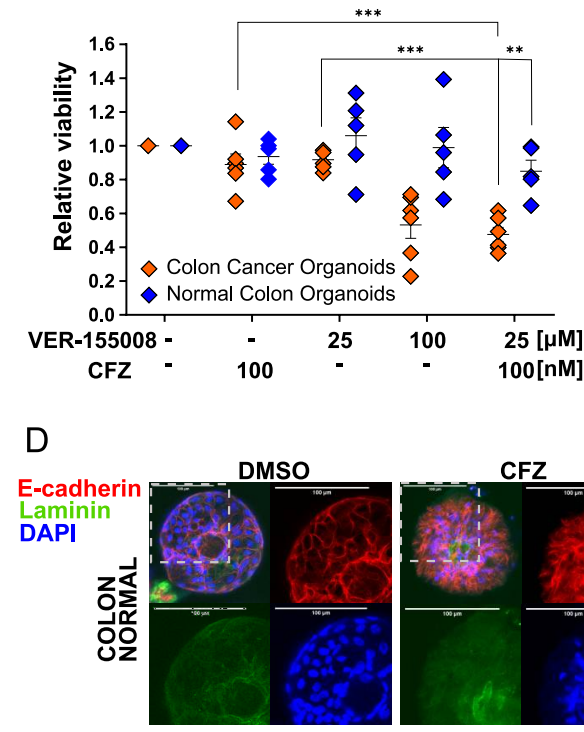

DMSO

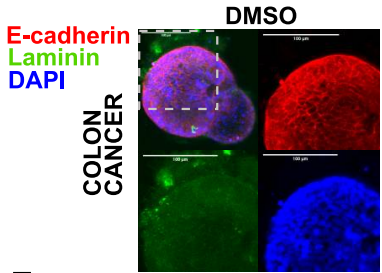

E

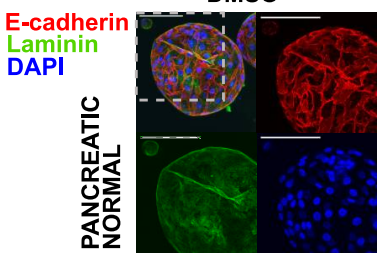

DMSO

E-cadherin DAPI

嵌

CFZ

CFZ

CFZ

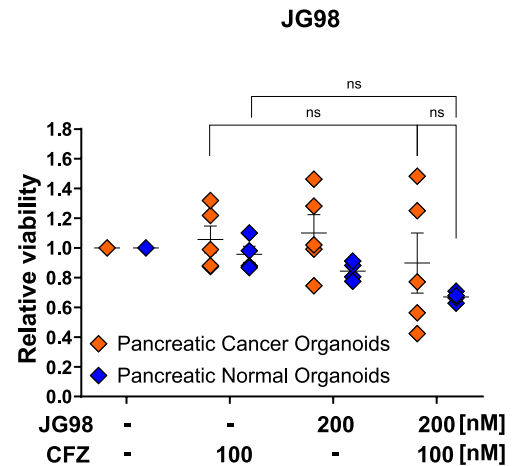

JG98
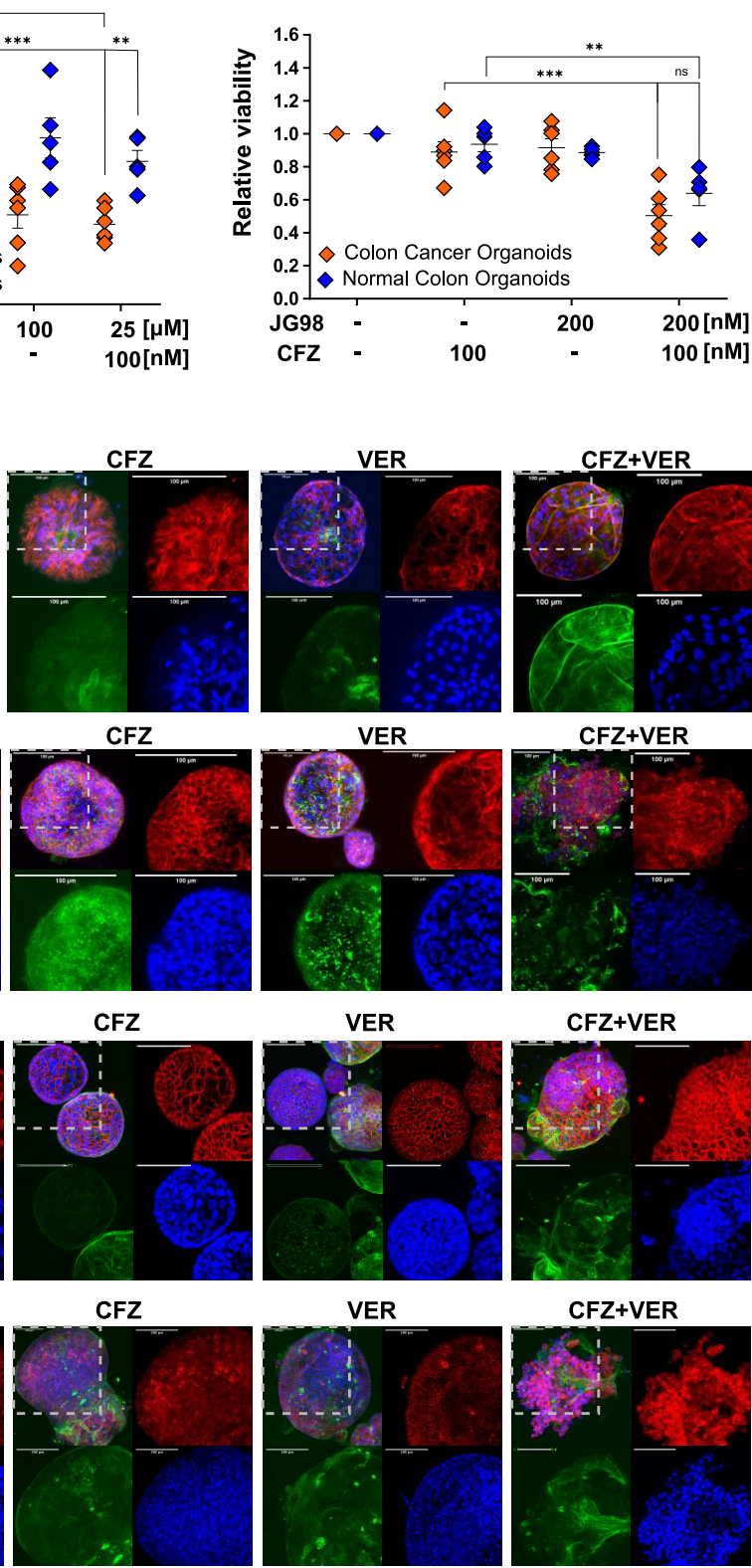

VER

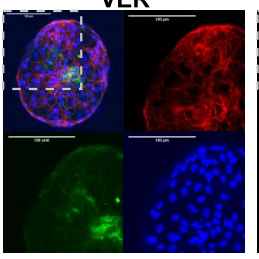

VER

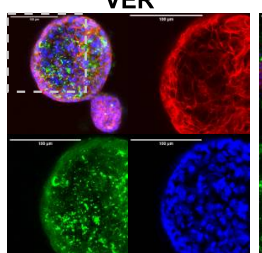

VER

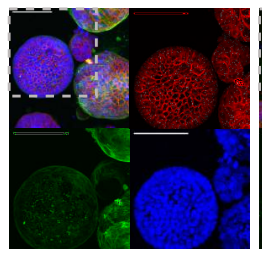

VER

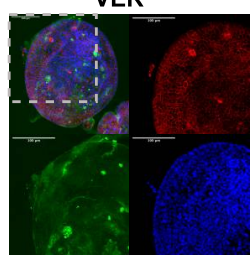

CFZ+VER

CFZ+VER

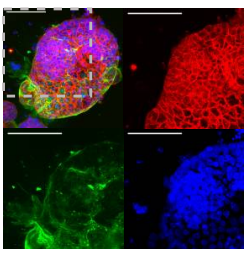

CFZ+VER

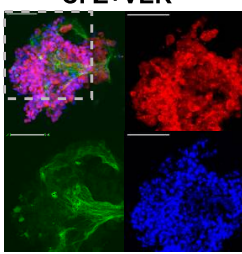

F

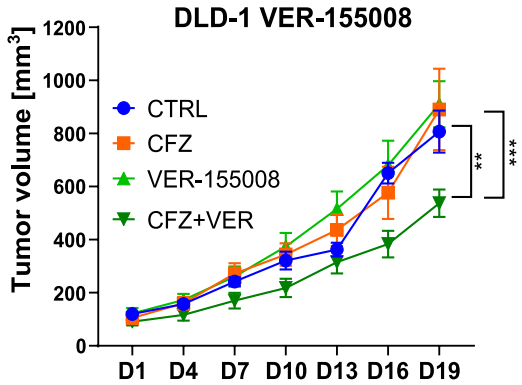

G

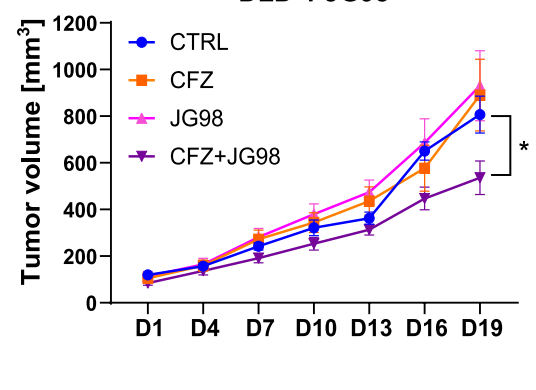

$\mathrm{H}$
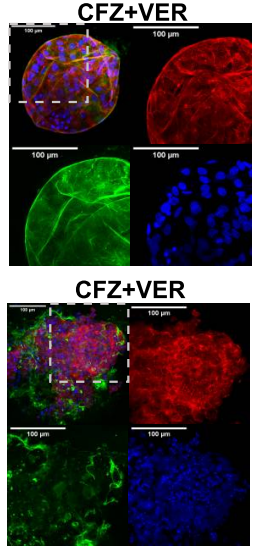

PANC-1

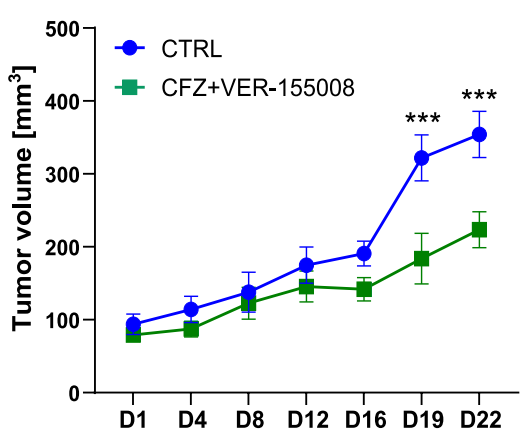

H-23

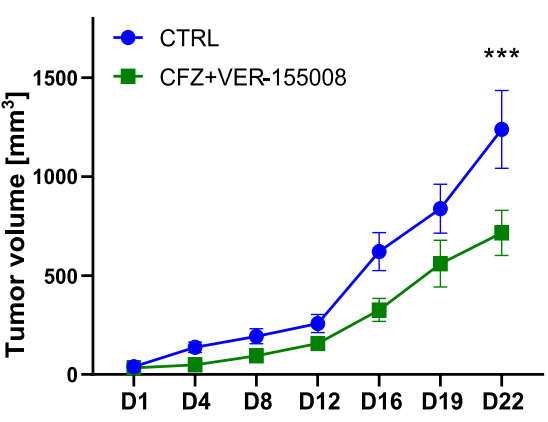


Figure 3 HSP70 inhibitors VER-155008 and JG98 specifically reduce cancer resistance to the proteasome inhibitor Carfilzomib

A, Viability of cancer cell lines (H-23, H1299 - lung; PANC-1, CAPAN-2 - pancreatic; RKO, DLD1 - colon) and normal fibroblasts treated with carfilzomib (CFZ) and HSP70 inhibitors VER-155008, JG98, and MAL3-101. Viability was measured with ATP-lite after 48h of treatment with indicated drug concentrations. Bars represent mean of $n=6$. Error bars represent SEM. Two-way ANOVA with Tukey's correction, ${ }^{*} \mathrm{p}<0.05 ; * * \mathrm{p}<0.01 ; * * * \mathrm{p}<0.001$.

B, C, Viability of colon and pancreatic organoids derived from tumor and normal patient's tissues. Organoids were treated with carfilzomib, VER-155008, and JG98 in indicated concentrations. Viability measured with ATPlite after 24h. Two-way ANOVA with Sidak's correction, ${ }^{*} \mathrm{p}<0.05$; $* * \mathrm{p}<0.01 ; * * * \mathrm{p}<0.001$.

D, E, Fluorescent microscopy of colon/pancreatic cancer and colon/pancreas normal organoids. Organoids were treated with carfilzomib and VER-155008 as indicated for $24 \mathrm{~h}$ and fixed for staining. Red - E-cadherin; Green - Laminin-5; Blue - DAPI. Scale bar represents $100 \mu \mathrm{m}$. Grey dashed square marks a fragment of the merged picture which is enlarged in a single-channel pictures. Corresponding phase contrast microscopy pictures of pancreatic colon and normal organoids are included in supplementary figure (Fig. S3C)

F, G, H, I, The size of subcutaneous xenografts formed in mice from DLD-1, PANC-1 and H-23 cancer cells. Indicated drugs were administered intraperitoneally: DMSO - control group, carfilzomib (CFZ) - $4 \mathrm{mg} / \mathrm{kg}$, VER-155008 - $35 \mathrm{mg} / \mathrm{kg}$, JG98 - $4 \mathrm{mg} / \mathrm{kg}$, VER+CFZ - $35 \mathrm{mg} / \mathrm{kg}+4 \mathrm{mg} / \mathrm{kg}$, $\mathrm{JG} 98+\mathrm{CFZ}-4 \mathrm{mg} / \mathrm{kg}+4 \mathrm{mg} / \mathrm{kg}$, diluted in $200 \mu 1$ PBS-5\% Tween-80. DLD-1 $-\mathrm{n}=6$ animals in every group, PANC-1 $-\mathrm{n}=7$ animals in every group, $\mathrm{H}-23-\mathrm{n}=5$ animals in every group. Error bars are SEM, test: two-way ANOVA with Sidak's correction, ${ }^{*} \mathrm{p}<0.05 ;{ }^{*} \mathrm{p}<0.01 ; * * \mathrm{p}<0.001$ 
bioRxiv preprint doi: https://doi.org/10.1101/2021.11.16.468807; this version posted November 18,2021 . The copyright holder for this preprint (which was not certified by peer review) is the author/funder. All rights reserved. No reuse allowed without permission.

Figure 4

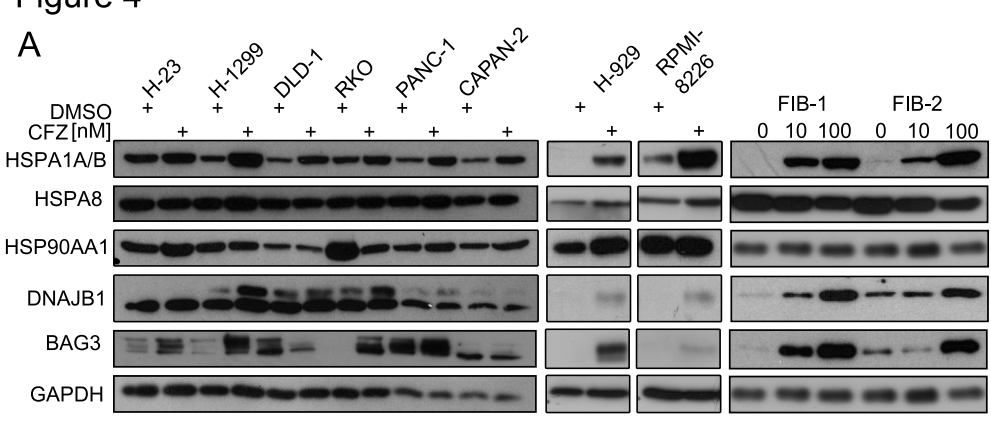

C
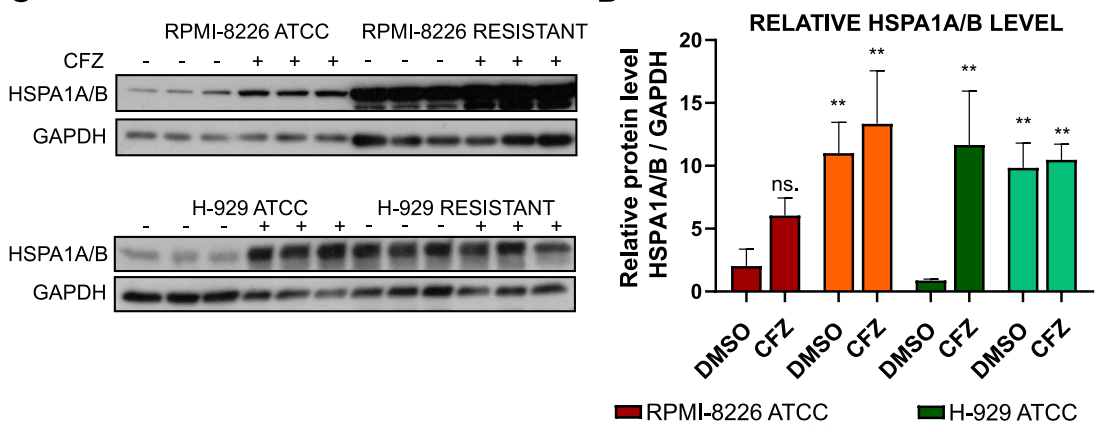

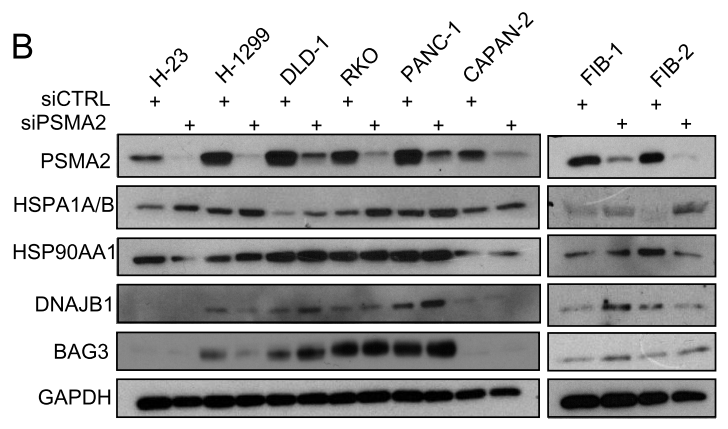

E

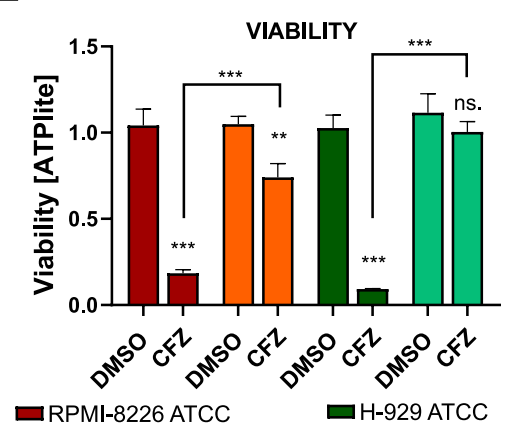

$\mathrm{F}$
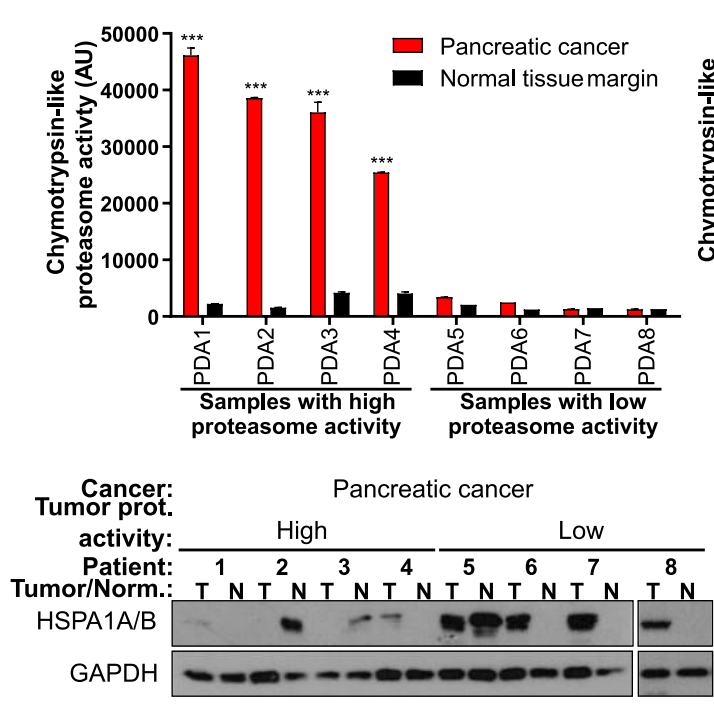

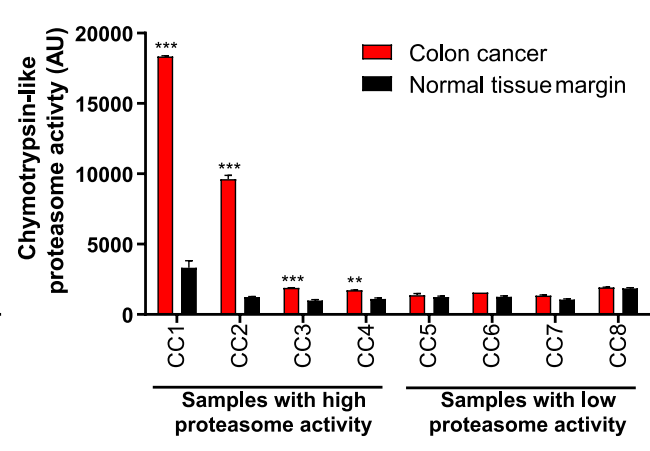

G Pancreatic cancer

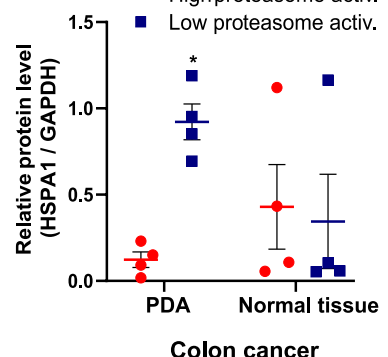

Colon cancer

- High proteasome activ

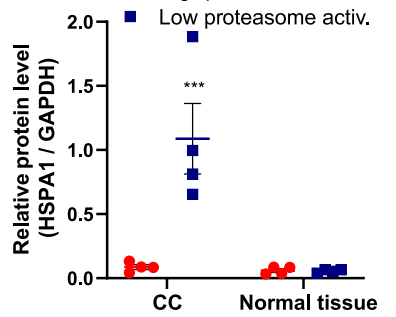


Figure $4 \mathrm{HSPA} 1 \mathrm{~A} / \mathrm{B}$ is upregulated under lowered proteasome activity conditions in human neoplasias.

A, Molecular chaperone protein levels in cancer, multiple myeloma, and normal fibroblast cell lines treated with carfilzomib for 24h (Concentrations as in Figure 1E unless stated otherwise) determined by western blot

B, Indicated molecular chaperone levels in cancer and normal fibroblasts transfected with siRNA targeting the proteasome subunit PSMA2, essential for the proteasome activity (see Fig. S4 for proteasome activity measurements).

C, H929 and RPMI-8226 multiple myeloma cell lines were selected cultured under increasing carfilzomib concentrations (up to $18 \mathrm{nM}$ and $24 \mathrm{nM}$ carfilzomib, respectively) over 3 months' time course, to obtain cells resistant to the proteasome inhibitor. Western blot shows HSP70 levels in primary (ATCC) and resistant (RES) cell lines treated with carfilzomib for 24h. In the case of RES cell lines they were grown for 5 days (one passage) without carfilzomib, prior to the DMSO or CFZ treatment.

D, Level of HSPA1A/B protein measured by densitometry relatively to GAPDH in the western blot in C.

E, Viability of primary and resistant multiple myeloma cell lines after treatment with carfilzomib, measured by the ATP-lite assay.

F, Chymotrypsin-like proteasome activity in 8 pancreatic (PDA) and 8 colon cancer (CC) patient tissue samples, and corresponding normal tissue samples from the healthy margin of the same patients. The samples were designated "high proteasome activity" if the chymotrypsin-like proteasome activity in cancer samples was significantly higher than in the corresponding normal tissue sample; western blot shows HSPA1A/B and GAPDH protein levels in the samples. For histopathology and clinical diagnosis see Fig. S4D.

G, Relative HSPA1A/B protein levels normalized to GAPDH protein levels in "high" and "low" proteasome activity sample groups from the western blot in F, in cancer and normal margin tissues;

$\mathbf{C}, \mathbf{D}, \mathbf{E}, \mathbf{F}$, Bars are means of $\mathrm{n}=3$ measurements with SD, test: two-way ANOVA with Bonferroni's correction, ${ }^{*} \mathrm{p}<0.05 ; * * \mathrm{p}<0.01 ; * * \mathrm{p}<0.001$; G, Horizontal, colored lines are means of $\mathrm{n}=4$ plotted values with SEM, test: two-way ANOVA with Sidak's correction, ${ }^{*} \mathrm{p}<0.05 ; * * * \mathrm{p}<0.001$; 
Figure 5

A

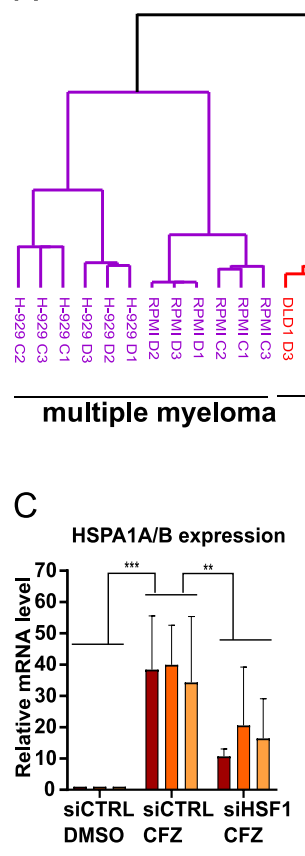

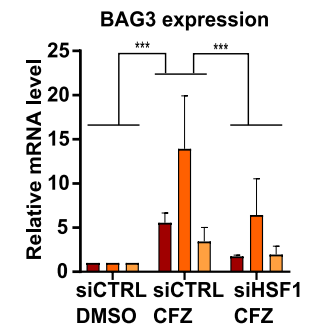

$\square$ H-23 $\square$ DLD-1 $\square$ PANC-1
HSP90AA1 expression

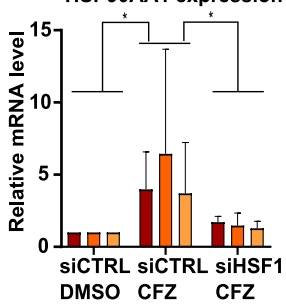

DMSO CFZ CFZ

$\square$ H-23 $\square$ DLD-1 $\square$ PANC-1
B

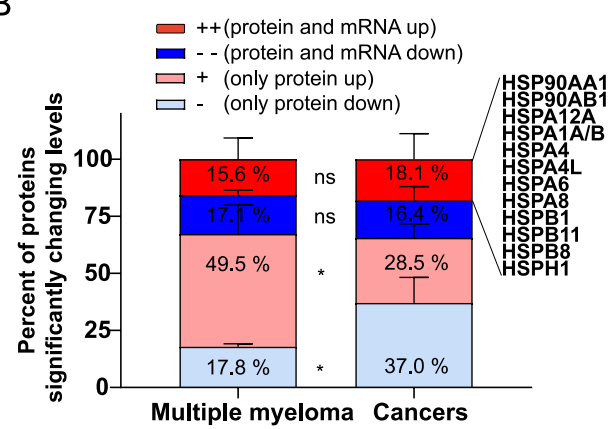

$\mathrm{E}$

Pancreatic cancer

- High proteasome activ.

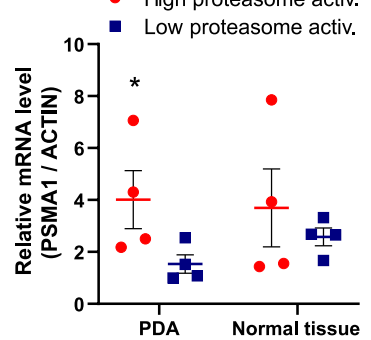

F
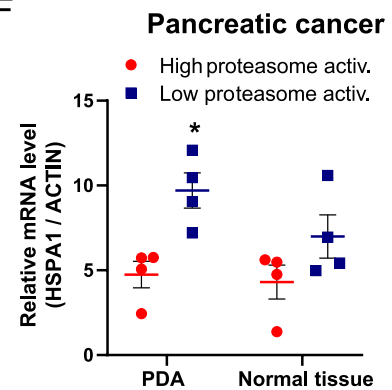

Colon cancer

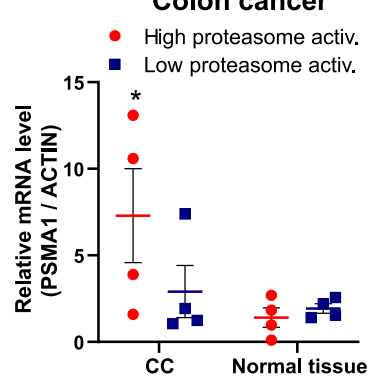

Colon cancer

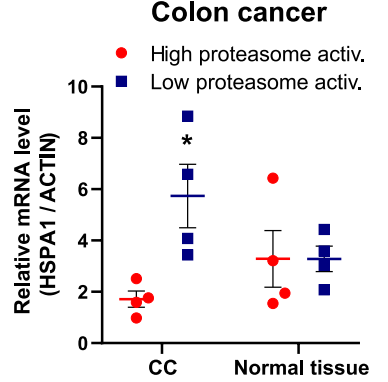

G Pancreatic cancer PSMA1 expression HIGH

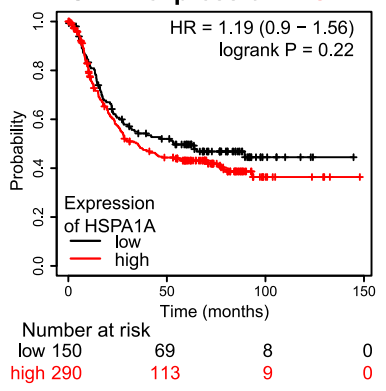

PSMA1 expression LOW

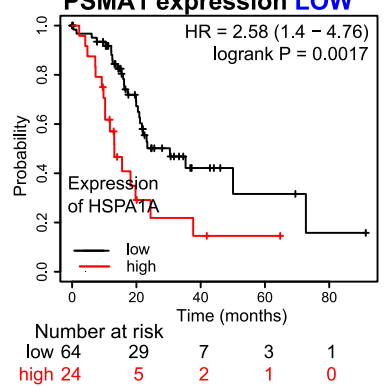

Colon cancer
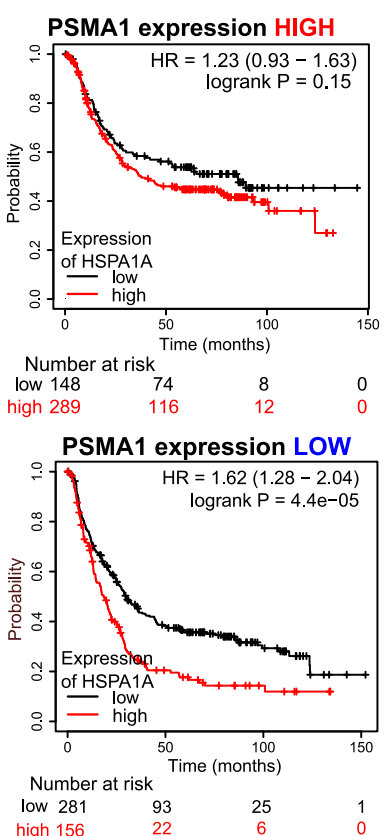
Figure 5 Transcriptional control of HSP70 expression in cancer cells upon the proteasome inhibition.

A, Hierarchical clustering (Euclidean distance) of transcriptomics results for 17311 mRNAs quantified in each of 36 transcriptomes from 8 indicated cell lines under control conditions (DMSO, D) or carfilzomib $24 \mathrm{~h}$ treatment $(\mathrm{C})$, each in $\mathrm{n}=3$ biological replicates (full data in Table S6). Carfilzomib concentrations were as described in Fig. 1E.

B, Matching of the significantly up- or downregulated proteins ( $<<0.05$, Table S3) to the mRNA significantly changing levels (FDR $<0.05$, Table S7) in cancer and multiple myeloma cell lines. Numbers of matched or unmatched proteins were transformed into percentages of all significant proteins in each cell line, means of these results were calculated ( $\mathrm{n}=2$ for multiple myeloma, $\mathrm{n}=6$ for cancer cell lines; cell lines as in a), and plotted as stacked bars with SEMs. Two-way ANOVA with Holm-Sidak's correction was used to compare corresponding protein groups between multiple myeloma and cancers, $* p<0.05$. A group of the molecular chaperones is indicated, present in the upregulated protein fraction matching the significantly upregulated mRNA in cancers.

C, Expression of HSPA1A/B, BAG3, HSP90AA1, DNAJB1 mRNA in the presence of carfilzomib (CFZ) and silenced HSF1 (siHSF1). H-23, DLD-1 and PANC-1 cancer cells were transfected with siHSF1 or siCTRL (negative control) and afterwards treated with carfilzomib (concentrations as in Fig. 1E). Expression of indicated genes was analyzed by qPCR. Bars represent mean of $n=3$ with SD. Two-way ANOVA with Tukey correction: $* \mathrm{p}<0.05 ; *{ }^{*} \mathrm{p}<0.01 ; * * \mathrm{p}<0.001$.

D, Representative western blot analysis of HSF1 silencing and levels of indicated chaperones in the presence of carfilzomib (CFZ) or DMSO control in the cell lines tested by qPCR in C.

E, Proteasome subunit PSMA1 mRNA relative levels in "high" and "low" proteasome activity sample groups from Fig. 4F, in cancer and normal margin tissues;

F, HSPA1A/B mRNA relative levels in "high" and "low" proteasome activity sample groups from Fig. $4 \mathrm{~F}$, in cancer and normal margin tissues;

E, $\mathbf{F}$ Horizontal, colored lines are means of $n=4$ plotted values with SEM, test: two-way ANOVA with Sidak's correction, ${ }^{*} \mathrm{p}<0.05$;

G, Association of the HSPA1A/B expression with patient's survival in pancreatic and colon cancer patients datasets (Methods) in samples with high or low (above/below median) expression of PSMA1, representing the proteasome expression. Red curve - high level of HSPA1A/B; Black curve - low level of HSPA1A/B. HR - hazard ratio; log-rank P - log-rank test P value for the curves comparison. Numbers below graphs indicate number of patients at risk - total and at consecutive time points; $\mathrm{n}=$ 528 for pancreatic cancer, $\mathrm{n}=874$ for colon cancer 
bioRxiv preprint doi: https://doi.org/10.1101/2021.11.16.468807; this version posted November 18,2021 . The copyright holder for this preprint (which was not certified by peer review) is the author/funder. All rights reserved. No reuse allowed without permission.

Figure 6

A

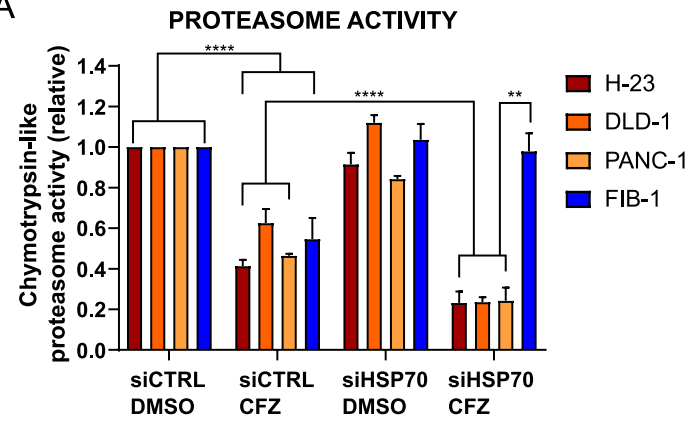

C

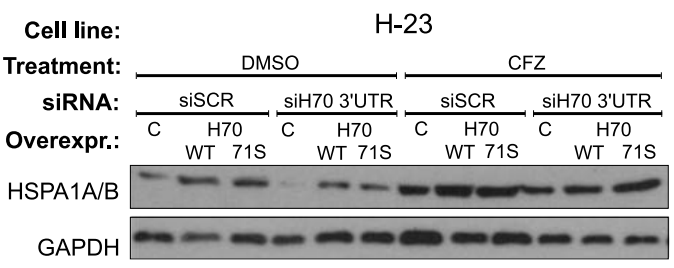

E

$$
\mathrm{H}-23
$$

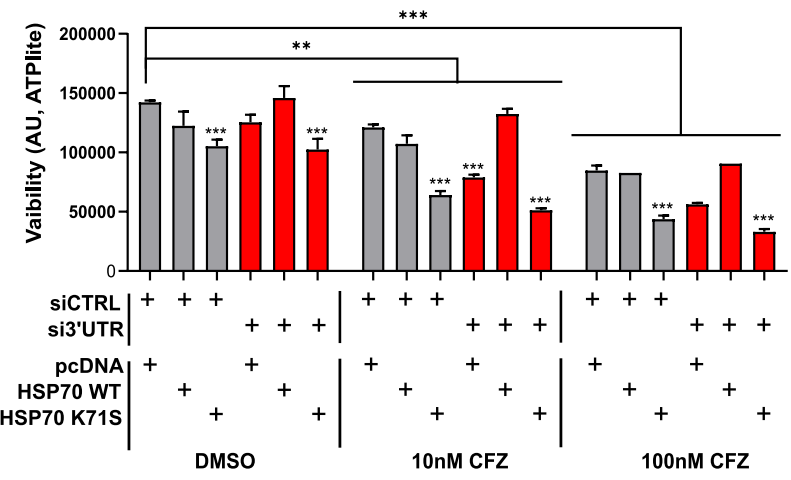

B

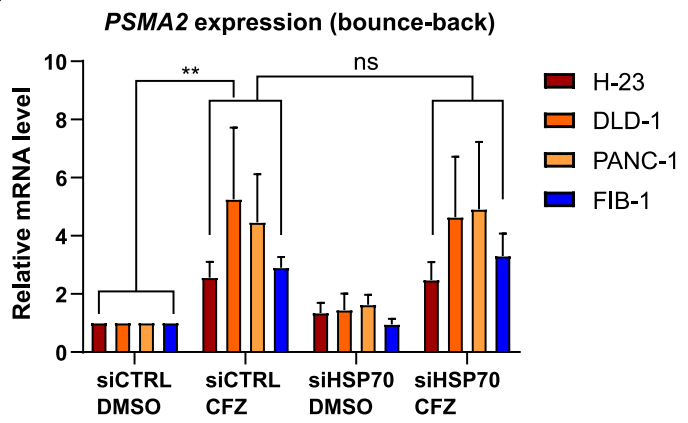

D

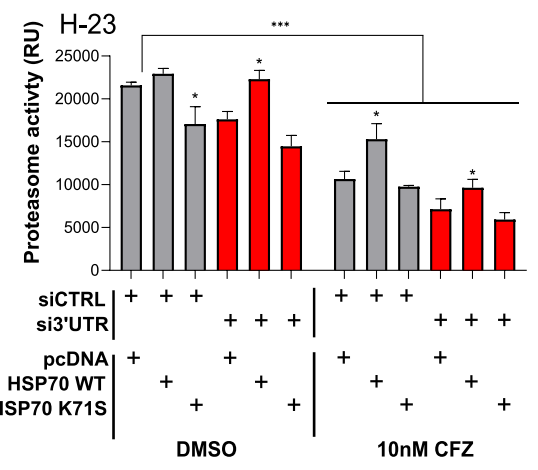

$\mathrm{F}$

Treatment: D C $\quad$ D $C$ C

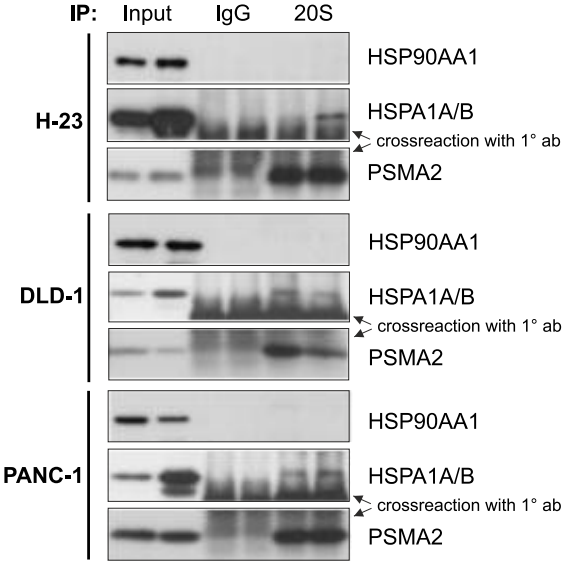

G

- DMSO $\square$ CFZ $100 \mathrm{nM} \square$ VER $400 \mu \mathrm{M}$

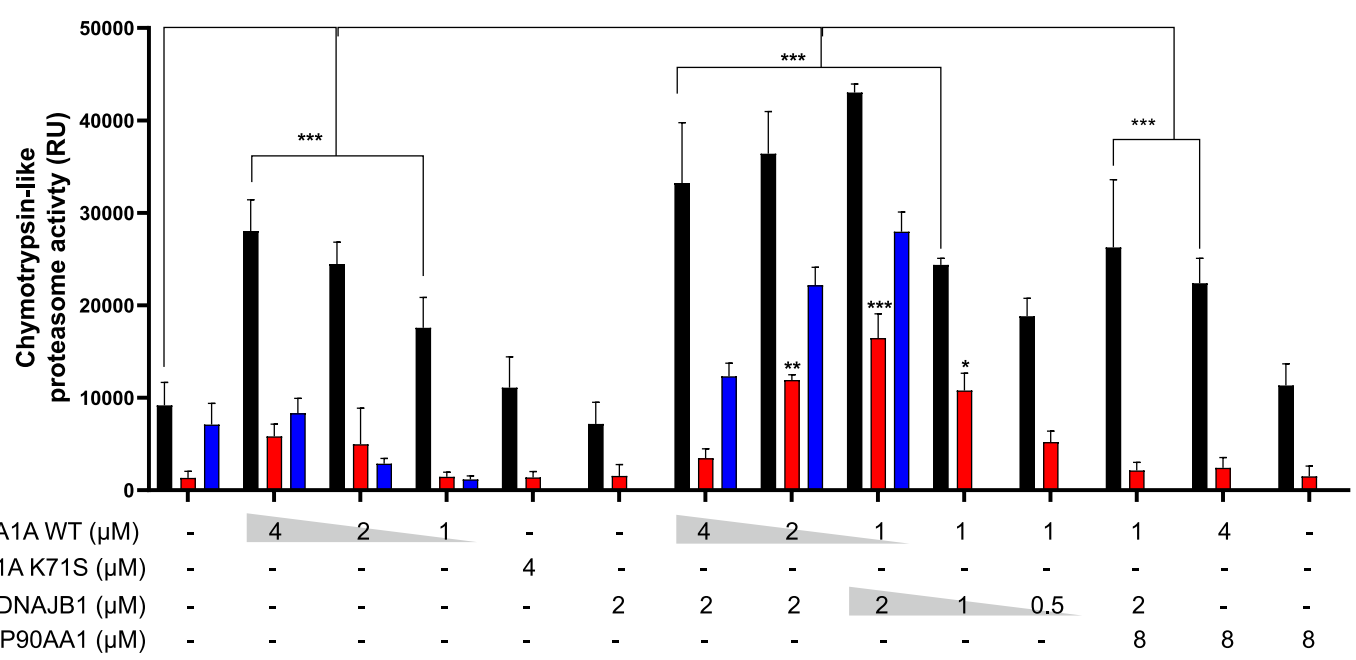


Figure $6 \mathrm{HSPA} 1 \mathrm{~A} / \mathrm{B}$ binds and chaperones the $26 \mathrm{~S}$ proteasome, increasing its activity and carfilzomib resistance in cancer cells.

A, Chymotrypsin-like proteasome activity upon carfilzomib treatment (concentrations for as in Fig. 1E) and silencing of HSPA1A/B (siHSP70) in the indicated lung, colon and pancreatic cancer and normal fibroblast cell lines; siCTRL - negative siRNA control. Bars are means of $n=5$ with SD.

B, Proteasome $20 \mathrm{~S}$ core subunit PSMA2 transcriptional bounce-back upon carfilzomib and silencing of HSPA1A/B (siHSP70) in the indicated lung, colon and pancreatic cancer and normal fibroblast cell lines; siCTRL - negative control. Bars are means of $n=4$ with SD.

C, Representative western blot demonstrating the silencing and the rescue overexpression of HSPA1A in H-23 lung cancer cell line. siCTRL - negative control; siH70 3'UTR - siRNA targeting 3'UTR of HSPAIA/B mRNA; H70 WT and H70 71S - vectors expressing HA-tagged wild type and K71S mutant of HSPA1A, respectively. Treatment with carfilzomib (CFZ) using concentrations as in Fig. $1 \mathrm{E}$.

D, Chymotrypsin-like proteasome activity in H-23 lung cancer cells upon silencing of $H S P A 1 A / B$ and rescue overexpression of wild type (WT) or mutant (K71S) HSPA1A in the presence of indicated carfilzomib concentrations. Bars are means of $n=2$ with SD.

E, Viability of H-23 lung cancer cells upon silencing of HSPA1A/B and rescue overexpression of wild type (WT) or mutant (K71S) HSPA1A in the presence of indicated carfilzomib concentrations. Bars are means of $\mathrm{n}=3$ with $\mathrm{SD}$.

F, Immunoprecipitation (IP) of the $20 \mathrm{~S}$ proteasome with HSP70A1A/B (present) and HSP90AA1 (absent), along with indicated unspecific IgG controls and inputs from H-23, DLD-1 and PANC-1 cell lines, treated for $24 \mathrm{~h}$ either with DMSO control (D) or carfilzomib (C) at $10 \mathrm{nM}, 20 \mathrm{nM}$ and $50 \mathrm{nM}$, respectively. Cross-reaction smears of the secondary WB antibodies with the immunoprecipitation antibodies are marked for clarity.

G, Purified human 26S proteasome (at $5 \mathrm{nM}$, purified from HEK293 cells) chymotrypsin-like activity in the presence of the indicated human molecular chaperones (recombinant, purified from E.coli), 100 $\mathrm{nM}$ carfilzomib and optionally $-400 \mu$ M VER-155008 HSP70 inhibitor. Bars are means of $\mathrm{n}=3$, and for VER-155008 n=2, with SD.

A-G, Two-way ANOVA with Tukey correction, ${ }^{*} \mathrm{p}<0.05 ; * * \mathrm{p}<0.01 ; * * \mathrm{p}<0.001$ 
bioRxiv preprint doi: https://doi.org/10.1101/2021.11.16.468807; this version posted November 18, 2021. The copyright holder for this preprint (which was not certified by peer review) is the author/funder. All rights reserved. No reuse allowed without permission.

Figure 7

A

$\mathrm{H}-23$ siCTRL SiHSP70

$\mathrm{CFZ}-+-+$

HSPA1A/B $-\mathrm{-a}$

IRE1

phos-IRE1

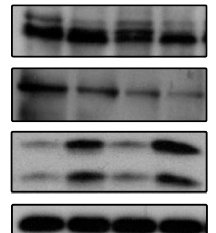

GAPDH

C

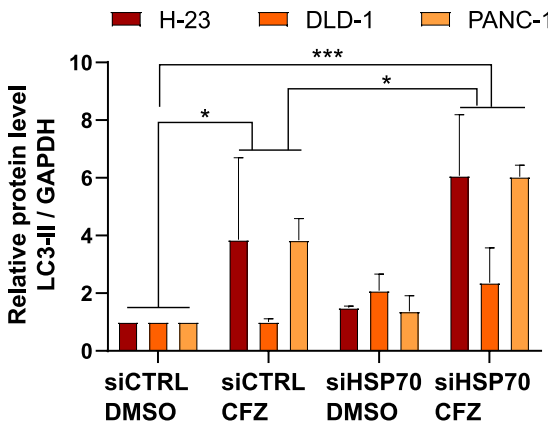

PANC-1

DLD-1 SiCTRL SiHSP70
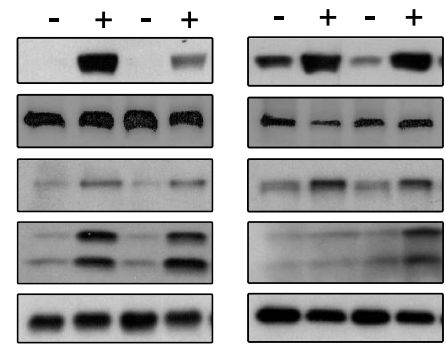

B

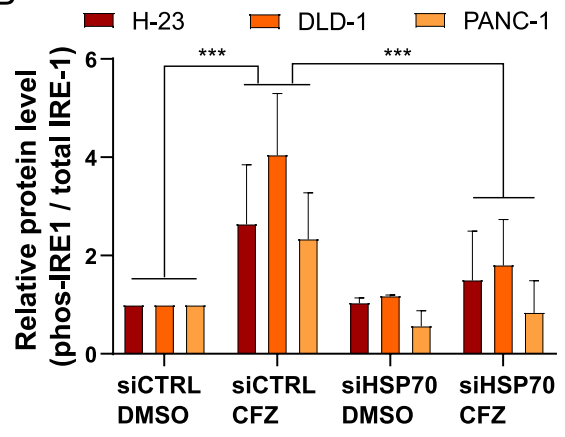

D

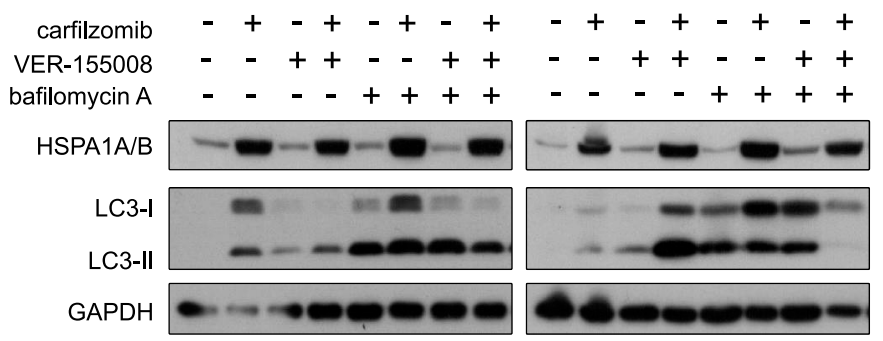

DLD-1

F
E

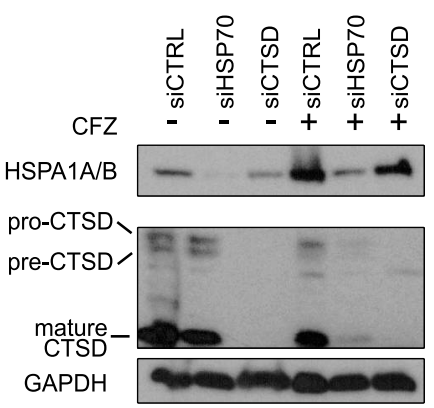

PANC-1
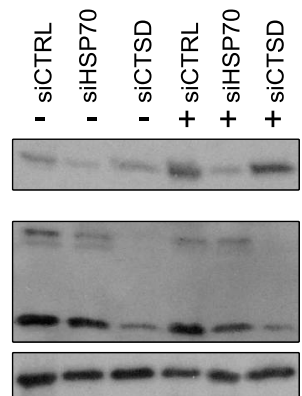
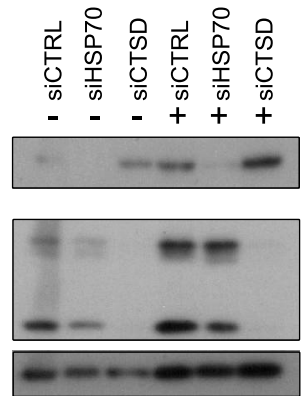

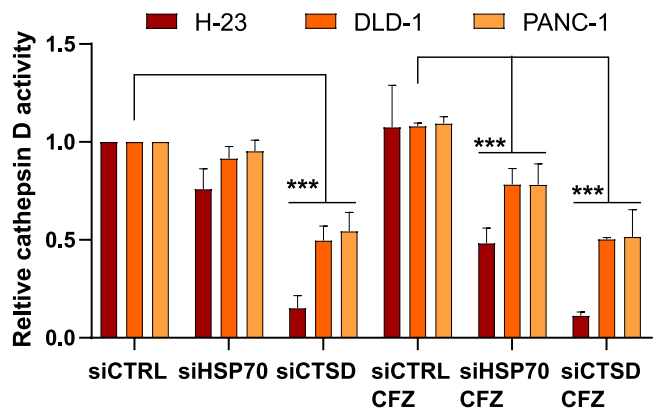

G

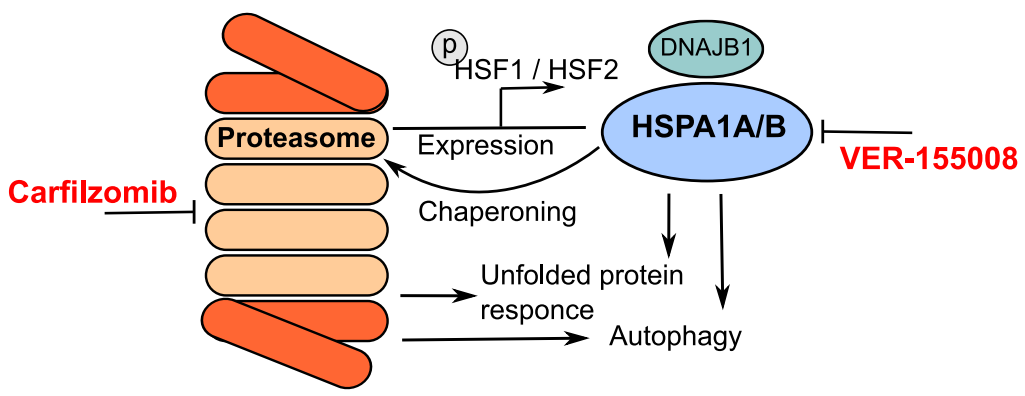


Figure 7 HSPA1A/B in involved in autophagy and unfolded protein response contributing to cancer resistance to proteasome inhibitors.

A, IRE-1 phosphorylation and LC3-I/LC3-II expression on HSPA1A/B (siHSP70) silencing and subsequent treatment with carfilzomib (CFZ) or control DMSO. Indicated cells were transfected twice day by day, treated with carfilzomib (concentrations as in Fig. 1F) a day after second transfection for $24 \mathrm{~h}$.

B, phospho-IRE-1 relative level on HSPA1A/B (siHSP70) silencing and subsequent treatment with carfilzomib. Bars means of $n=3$ independent experiments of band intensities from western blot. Twoway ANOVA with Tukey's correction, *p $<0.05 ; *$ p $<0.01 ; * * \mathrm{p}<0.001$

C, LC3-II relative level on HSPA1A (siHSP70) silencing and subsequent treatment with carfilzomib. Bars means of $n=3$ independent experiments of band intensities from western blot. Two-way ANOVA with Tukey's correction, ${ }^{*} \mathrm{p}<0.05 ;{ }^{* *} \mathrm{p}<0.01 ;{ }^{* * *} \mathrm{p}<0.001$

D, LC3-I/LC3-II expression in indicated cell lines upon treatment with inhibitors: carfilzomib 100 $\mathrm{nM}$, VER-155008 $50 \mu \mathrm{M}$, bafilomycin A $20 \mathrm{nM}$ for $24 \mathrm{~h}$.

E, Cathepsin D (CTSD) level on HSPA1A/B (siHSP70) silencing and subsequent treatment with carfilzomib. siCTSD used as a control for cathepsin D activity test (e).

F, Cathepsin D activity on HSPA1A (siHSP70) silencing and subsequent treatment with carfilzomib. Two-way ANOVA with Dunnett's correction, ${ }^{*} \mathrm{p}<0.05 ; * * \mathrm{p}<0.01 ; * * * \mathrm{p}<0.001$

G, Diagram summarizing the participation of HSP70 in the processes contributing to the resistance of cancer cells to proteasome inhibition. 